\title{
Joint spatial mapping of childhood anemia and malnutrition in sub-Saharan Africa: a cross-sectional study of small-scale geographical disparities
}

\author{
Rasheed A Adeyemi ${ }^{1}$, Temesgen Zewotir $^{2}$, Shaun Ramroop ${ }^{1}$
}

1. School of Mathematics, Statistics and Computer Science, University of KwaZulu-Natal, Pietermaritzburg campus, Scottsville 3209, South Africa.

2. School of Mathematics, Statistics and Computer Science, University of KwaZulu-Natal, Westville campus, Durban, South Africa.

\begin{abstract}
Background: In epidemiological studies, several diseases share common risk factors or co-exist in their spatial prevalence. Disease mapping allows the health practitioners and epidemiologists to hypothesize the disease aetiology and gain better understanding of the geographical prevalence of the disease risks.

Objective: This paper investigates the differences in small scale geographical variations and the underlying risk factors of child's health outcomes (anemia, stunting and wasting) in Sub-Saharan Africa using spatial epidemiology.

Method: The study first carried out an independent univariate analysis on each malnutrition indicator to identify underlying risk factors. A multivariate conditional autoregressive prior was explored to jointly model the spatial correlation between the undernutrition indicators and the small area-geographical disparities at sub-national levels in two sub-Saharan African countries.

Results: The approach was implemented on data from National cross-sectional household- based demographic and health surveys conducted in 17,307 under-five children in Burkina Faso and Mozambique in 2010-2012. Out of these children, 31.8\% are found to be stunted, 15.5\% wasted and 30.9\% had anemia among Burkina Faso children, while 42.5\% of Mozambican children were stunted, 5.9\% wasted and $30.9 \%$ suffered from iron-deficiency anemia. The multivariate analysis revealed that the spatial prevalence existed across regions in Burkina Faso with geographical variations in stunting estimated as: 0.7549 , CI $(0.4693,1.264)$; wasting $0.9197 ;(95 \% \mathrm{CI}: 0.535,1.591)$ and anemia : 0.734; $(0.4606,1.214)$. In additin, the spatial correlation between stunting and wasting was negatively correlated: -0.998 ; $95 \%$ CI $(-1.000$, -0.984), and a perfect negative correlation;(-1) between stunting and anemia, and positive for wasting and anemia: $0.997 ;(0.978,1.000)$. The spatial occurrence across provinces in Mozambique indicated that there was strong positive correlation between stunting and wasting; 0.986 ; $(0.899,1.000)$ and a significant negative correlation between stunting and anemia: $-0.720,(-0.934,-0.308)$ and wasting and anemia: -0.640 ; (-0.903 -0.174) with individual geographical variability in child stunting: 1427, (913.6, 2268); wasting:1751, (1117, 2803) and anemia: 556, $(279.5,978.9)$. These extra random effect parameters computed in our multivariate approach would outperform a univariate analysis in similar studies. Our model further detected high prevalent of malnutrition and anemia in the northern Burkina Faso, but high anemia prevalent found in central Mozambique, and high stunting and wasting identified Southern Mozambique. In addition, the risk factors of malnutrition and iron deficiency anemia included household poverty, morbidity, short birth interval (less 18 months), breast feeding, antenatal attendance and maternal literacy.

Conclusion: The statistical relevance of the identified risk factors in this study is useful to target specific individual interventions and the maps of the geographical inequalities in sub-national region can be used for designing nutrition interventions and allocation of scarce health resources.
\end{abstract}

Keywords: Joint spatial mapping, childhood anemia, malnutrition, sub-Saharan Africa.

DOI: https://dx.doi.org/10.4314/ahs.v19i3.45

Cite as: Adeyemi RA, Zewotir T, Ramroop S. Joint spatial mapping of childhood anemia and malnutrition in sub-Saharan Africa: a cross-sectional study of small-scale geographical disparities. Afri Health Sci. 2019;19(3): 2692-2712. bttps:/ / dx.doi.org/10.4314/ ahs.v19i3.45

\section{Corresponding author:}

Rasheed A Adeyemi,

School of Mathematics, Statistics and Computer

Science, University of KwaZulu-Natal,

Pietermaritzburg campus, Scottsville 3209,

South Africa.

Email: adeyemira@yahoo.ca

\section{Introduction}

Child malnutrition and anemia are both global public health problems with monumental consequences at adulthood. The prevalence of stunting is declining and according to UNICEF, $40 \%$ (257 million) of the world's children in 1990 suffered from stunting whereas in 2013, the proportion had decreased to $25 \%$ (161 million $)^{1}$. The prevalence of wasting has also significantly declined,

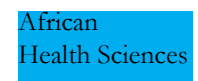

(C) 2019 Adeyemi et al. Licensee African Health Sciences. This is an Open Access article distributed under the terms of the Creative commons Attribution License (https://creativecommons.org/licenses/BY/4.0), which permits unrestricted use, distribution, and reproduction in any medium, provided the original work is properly cited.

African Health Sciences Vol 19 Issue 3, September, 2019 
from 19\% (122 million) in 1990 to 8\% (51 million) in 2013. In 2008, over 1 billion people worldwide were said to be malnourished ${ }^{2}$ and 2 billion people are globally affected with anemia ${ }^{3}$. Recent reports have shown that Africa and Asia accounted for more than $85 \%$ of the absolute anemia burden in high-risk groups and a quarter of the global population, including 293 million (47\%) children younger than 5 years, and women of reproductive age, $42 \%$ in pregnant women, and 468 million (30\%) non-pregnant women ${ }^{4}$.

Malnutrition is a condition that arises as a result of consuming a diet that contains insufficient or too many nutrients or as a result of faulty or under-utilization of foods. Anthropometric indices are commonly used in order to classify individuals as malnourished or of normal nutritional status. Stunting (short height- for- age) is an indicator of linear growth retardation and cumulative growth deficits in children (chronic malnutrition), wasting is measured by low- weight-for-height score and it describes the body mass in relation to height for current nutritional status, and it is commonly referred to as acute malnutrition. Both measures depict important public health indicators. Child malnutrition is known to be a leading contributor to under-five mortality and it results from inadequate nutrients from food intake, chronic diseases and infection may also lead to mild to moderate anemia ${ }^{5-7}$. Approximately 800,000 deaths are attributed to wasting and over one million is caused by stunting ${ }^{8}$. Wasting and stunting are also responsible for the loss of 64.6 and 54.9 million Disability Adjustment Life Years (DALY) respectively, accounting for $14.8 \%$ and $12.6 \%$ of the global DALYs for children ${ }^{8}$. Childhood stunting and wasting contribute separately to mortality and burden of disease ${ }^{8}$.

Anemia is usually described as multifactorial in origin, and malnutrition arising from infectious disease, inherent haemoglobinopathies ${ }^{9}$ and thalassaemias ${ }^{10}$, which are identified as the major contributor. In many regions, micro-nutrient deficiency is a problem, particularly iron, vitamin $A$ and zinc deficiency and about 50 percent of all anemia cases are due to iron deficiency ${ }^{11}$. Anemia in infancy and young children is associated with reduced cognitive development ${ }^{12}$, growth retardation ${ }^{13}$ and immune function14 and survival.
Evidently, the planning for resource allocation to control child malnutrition and anemia is based on prevalence data from field surveys within country, which are often extrapolated to the country as a whole ${ }^{15}$. However, efficient health intervention and programs to control child under nutrition including micro-nutrient deficiency in young children require target approaches based on information on the geographical distribution at the sub-regional level or high-risk communities and better understanding the relative contribution of the major underlying factors. Geographical differences in the causes of anemia and malnutrition can be partially explained by large-scale variability in environmental factors, particularly nutritional and infection causes. Studies have established environmental drivers of anemia and childhood malnutrition tend to show a certain degree of spatial dependence i.e. geographical clustering ${ }^{15-17}$.

For decades, the issues of spatial modeling and developments have focused mainly on the modeling of a single disease. The spatial mapping model has long been used to understand the geographical variation in disease rates ${ }^{18}$, which makes it easier to describe places of unusually high risk and produce a contiguous map of disease risk to guide decision makers. Nowadays, joint mapping provides useful information on the similarity of the common risk factors and the approach is more appealing than the univariate response analyses. The potential benefits of a multivariate disease mapping include improvement in the precision of the underlying risk pattern estimation and quantify shared and specific patterns of risk among different diseases ${ }^{18-20}$. A good review of multiple disease mapping and techniques can be found in existing literature ${ }^{20,21}$ and the model framework rely on the ability of an area to borrow information from the neighboring regions ${ }^{22}$. The aforementioned studies have motivated the present study and we extend the spatial modeling approach to multivariate setting. Accordingly, this study therefore explores multivariate conditional auto-regressive approach to simultaneously model the three malnutrition indicators among children less than five years of age.

The paper is then structured into sections. In section 2 , the geographical location of the study area and the DHS data was detailed. Section 3 discussed the model formulation and construction of joint multivariate model for binary response and Bayesian estimation procedures. Sec- 
tion 4 presents the results from the implementation of the proposed method on cross-sectional data obtained from DHS and presented the results. Section 5 discussed the results and last section gives a concluding remark.

\section{Methods}

\section{Study area and data source}

The data used in this study were obtained from Demographic and Health Surveys (DHS) as domiciled in the Bureau of Statistics of respective countries. Over the years, the DHS program has provided technical support and funding to conduct surveys in many low income countries. The program has promoted global understanding of health and population trends. They developed standard procedures, methodologies and manuals to guide the sampling survey planning, design and data collection processes to obtain quality data and reflect the health and demographic representation of the population comparable among countries. The data used in this study are extracted from the surveys of Burkina Faso Demographic and Health Survey and Multiple Indicators $\left(\right.$ DHS $^{23}$ and Mozambique ${ }^{24}$.

Figure 1(a) and(b) shows the geographical maps of regions(provinces) in Burkina Faso and Mozambique respectively.

Burkina Faso is a landlocked country in West Africa. It covers an area of around $274,200 \mathrm{~km}^{2}$ and it has 13 regions and subdivided into 45 administrative provinces ${ }^{25}$. The Burkina Faso has a population of about 18.1 million $^{26}$. Mozambique is a country in Southeast Africa bordered by six countries and the Indian Ocean. According to the 2017 World Population Prospects, Mozambique has a total population of 28.8 million $^{26}$ and a total fertility rate $^{24}$ of 5.9. Mozambique is made up of 10 administrative provinces and a total landmass of $799,380 \mathrm{~km} 2$

\section{Variables considered in the study}

In this study, data information from Demographic and Health Surveys of two countries were assessed and analyzed. Anemia is described as a product of low level concentration of functional hemoglobin $(\mathrm{Hb})$ in the blood. According to the World Health Organization (WHO), children whose age range from 6-59 months are considered anemic if their $\mathrm{Hb}$ concentration levels are below
$11.0 \mathrm{~g} / \mathrm{dl}^{27}$. The study also adopted the 28 standard measure for characterization of child malnutrition: weightfor-height (wasting) and height-for-age (stunting) $z$ scores as when the child Z- score falls below minus $2 \mathrm{SD}$, the child is considered as wasting or stunting respectively.

The following variables are also chosen used in existing empirical studies of childhood malnutrition as suggest$\mathrm{ed}^{29,30}$. The factors included in our model are(a) child use bed net (1), 0- not(reference) (b) the child's age (in months) categorized as: $1-5$ months, 6-11 months, 12-23 months and $\geq 24$ months (reference); (c) birth within 3 years is categorized as: $\leq 1$ child, $\geq 2$ or more children (d) child's sex male $=1$, female $=0$ (reference), (e) had morbidity (diarrhea, fever, cough and pneumonia, 2 weeks prior to the survey) yes $=1$, no $=0$ (reference) and (h) measles vaccination, yes $=1$, no $=0$ (reference). Maternal factors considered include (f) mother's literacy (ability to read and write $)=1$, not literate $=0$ (reference); (g)maternal age (in years) used as continuous variable in the model; and (h) antenatal class attendance categorized as (i) No visit, (ii) 1 to 3 visits (iii) 4 and more visits(reference)during pregnancy. The socio-economic variables included in the analysis are: (i) place of residence (rural=1, urban=0); and (ii) mother's wealth index categorized as: poorest(reference), poor, middle, richer, richest and (iii) access to electricity yes $=1$, no $=0$ (reference $)$.

\section{Joint disease modeling}

The shared component models have been commonly applied to jointly model risk of oral and esophageal cancers $^{31}$, chronic obstructive pulmonary disease(COPD) and lung cancer ${ }^{32}$, sudden infant mortality and causes of death in Austria ${ }^{33}$, ecological comorbidity modelling of childhood diseases in Somalia ${ }^{34}$, infant mortality from four cancers 20 and gender inequalities in hospital admission for chronic diseases ${ }^{35}$. However, analysts can decide to use a multivariate normal model approach to access co-variances and correlation within and between diseases of underlying spatial risk ${ }^{22,32}$. The introduction of a new joint modeling paradigm known as the shared component model by ${ }^{31}$ and subsequent extension of their work to joint disease clusters detection. Other studies employed multiple-membership multiple-classification (MMMC) models for assessing social network dependence in an individual response to academic performance by including 
other group dependence such as the school or area to which an individual belongs $\mathrm{s}^{36,37}$ and in adolescent Health Study data set $^{38}$.

However, a multivariate joint analysis permits the estimation of conditional correlation between two health outcomes while at the same time, facilitates the determination of the spatial association with the region. Estimating the joint spatial distribution of multiple diseases will better outperform the underlying risks than it would be obtained from the univariate analysis. For example, recent developments of theory and applications of multivariate joint modelling can be found in the literature ${ }^{39-41}$ and a scale mixture approach for spatial dependence was proposed $\mathrm{by}^{42}$ as a recent contribution in this field.

\section{Model building}

In this section, the reviewed models are adopted to suit the Bernoulli data at hand. Let yijk be the disease (nutritional status) coded $(0 / 1)$ of a disease $k$, where $k=1$ for stunting, $\mathrm{k}=2$ for wasting, and $\mathrm{k}=3$ for anemia for individual child $i, i=1,2, \ldots, n j$, in regions $j$ (provinces as the case may be). We further assume that the observed outcomes arise from a trivariate distribution, with pijk as the probability of disease $\mathrm{k}$ occurring in individual in area $j$. The data generation model is defined as

$y_{i j k} \sim \operatorname{Bernoulli}\left(p_{i j k}\right) \quad$ (1) and for each model, the covariates are introduced as stated below.

In the separate analysis, the covariates and random effects are introduced as follows:

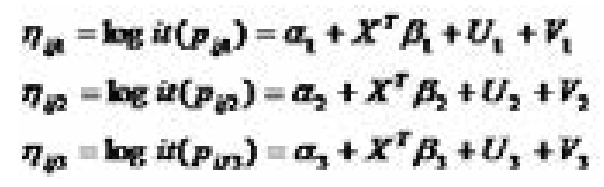

Where $U_{1}, U_{2}$, and $U_{3}$ are structured spatial random effects modeled by independent conditional auto-regres-

sive prior, while $V_{1}, V_{2}$, and $V_{3}$ are unstructured random effects modeled by independent normal distributions, known as convolution model , i.e. Besag, York and Mollie (BYM) model

In the a shared component model approach, the covariates and random effects are introduced as follows in two disease case scenarios

$$
\begin{aligned}
& \eta_{i j 1}=\log i t\left(p_{i j 1}\right)=\alpha_{1}+X^{T} \beta_{1}+U_{1} \delta+U_{2} \\
& \eta_{i j 2}=\log i t\left(p_{i j 2}\right)=\alpha_{1}+X^{T} \beta_{2}+\frac{U}{\delta}
\end{aligned}
$$

where $U_{1}$ is the shared component and is the component specific to the first disease only. These two components are modeled using conditional autoregressive priors with precision, $\tau 1$ and $\tau 2$ respectively.

In the case of a multivariate joint model approach, one can easily extend into three outcomes. In the multivariate setting, the covariates and random effects are introduced as follows

$\eta \ddot{i j} 2=\operatorname{logit}($ pij1 $)=\alpha 1+\mathrm{XT} \beta 1+\varphi \mathrm{i}$

$\eta$ ij $3=\operatorname{logit}($ pij 2$)=\alpha 2+\mathrm{XT} \beta 2+\varphi \mathrm{i}$

$\eta \mathrm{ij} 1=\operatorname{logit}(\mathrm{pij} 3)=\alpha 3+\mathrm{XT} \beta 3+\varphi \mathrm{i}$

The multivariate joint modeling approach can be easily generalized to more than two outcomes. In the multivariate setting, the covariates and random effects are introduced as follows

where $\varphi=(\varphi 1, \varphi 2, \varphi 3) \mathrm{T}$ is modeled using a multivariate conditional autoregressive prior that is $\Phi \operatorname{MCAR}(1, \Sigma)$,

and where $\Sigma$ is the covariance matrix including correlation.

In order to induce spatial correlation structure between the set of binary logistic models, equations (2) can be fused together into a multivariate version, and the matrix form explicitly expressed as

$$
\left(\begin{array}{l}
\log i t\left(p_{i j 1}\right) \\
\log i t\left(p_{i j 2}\right) \\
\log i t\left(p_{i j 3}\right)
\end{array}\right)=\left(\begin{array}{l}
\alpha_{1} \\
\alpha_{2} \\
3_{1}
\end{array}\right)+X\left(\begin{array}{l}
\beta_{i 1} \\
\beta 2 \\
\beta_{i 3}
\end{array}\right)+\left(\begin{array}{l}
\phi_{1} \\
\phi_{2} \\
\phi_{3}
\end{array}\right)
$$

We then model y1ij,y2ij,andy3ij via the following tri-variate normal distribution

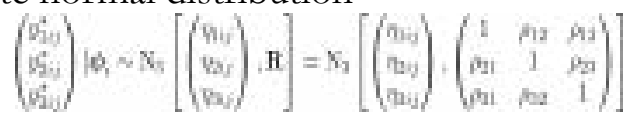

where $\alpha_{k}, k=1,2,3$ in equation (3) represents individual specific disease intercept, and the terms $\beta=(\beta 1, \beta 2, \beta 3) \mathrm{T}$ are $\mathrm{p} \times 1$ vectors of regression parameters to the set of covariates (fixed effects) are presented in Table of posterior estimates. $\mathrm{R}$ is a within-subject correlation matrix with diagonal elements set to 1 for identifiability and off diagonal $\varrho$ denoting the conditional correlation between y1ij, $y 2 \mathrm{ij}$, and $\mathrm{y} 3 \mathrm{ij}$ given as $\varphi \mathrm{i}$ and $\varphi \mathrm{i}=(\varphi 1, \varphi 2, \varphi 3) 0$ is a 3 $\times 1$ vector of spatial dependent random effects for the ith region or province as presented in Table 2 and 6) for Burkina Faso and Mozambique respectively.

Model estimation was carried in a full Bayesian approach by assigning appropriate prior distributions to all the parameters of the models. In addition to the priors given to the random effects discussed in the models above, non-in- 
formation priors were assigned to the regression coefficients. For the intercepts, diffuse priors were assumed, that is, $\mathrm{p}(\alpha \mathrm{k})$, while for the covariate coefficients, highly dispersed normal prior distributions were assumed, that is, $\mathrm{p}(\beta) \sim \mathrm{N}(0,104)$.

In a shared component model, the analyst needs to specify an extra parameter $\delta$ by allocating a prior as $\log \delta \sim(0$, $\sigma 2)$, while in the case with multivariate setting, the covariance matrix was assigned an inverse Wishart prior as $\Sigma$ $\sim \operatorname{IW}(\mathrm{r}, \mathrm{R})$ with $\mathrm{R}$ considered to be an identity matrix. All model was fitted using WinBUGS software ${ }^{43}$.

There are two ways of proceeding, via the covariance matrix or its reciprocal. One way is to specify the joint distribution (??) and assume specific forms for $\Sigma$. For more readings, see ${ }^{39,44}$.

\section{Model specification}

We performed separate independent univariate analysis for each malnutrition indicator to assess demographic risk factors associated with the child malnutrition status. Data cleaning and re-coding was done in $\mathrm{R}^{45}$, and the univariate analysis was carried out via a Bayesian Approximation using the Integrated Nested Laplace Appropriation(IN$\mathrm{LA})^{46}$. The Shapefile data of the geo-reference coordinates of countries was downloaded at Global Administrative Areas ${ }^{47}$ and the maps of the posterior estimates of the models was done using R-INLA environments. The following models to investigate the socio-demographic factors.

- $\mathrm{M} 1: \eta \mathrm{i}=\mathrm{x} 0 \beta$

- M2: $\eta=\mathrm{x} 0 \beta+\mathrm{f} 1(\mathrm{zi})+\varphi \mathrm{i}+\theta \mathrm{i}$

where, the set of observations $\left(\mathrm{x}_{\mathrm{i}}\right)$ represents categorical covariates, zi continuous variable and, si represents the index of geographical location split into unobserved(unstructured) spatial and structured (correlated) random effects.

- $\quad$ Model M1, (i.e. usually pure linear model) which is represented as the baseline model where all parameters assumed fixed effect regression model,

- Model M2, (i.e. structured additive regression model), which includes linear and non-linear covariates, unstructured and structured(correlated) effects.
In order to account for the variability or 'noise', which are not measurable by the categorical and continuous covariate factors, many different approaches to spatial smoothing have been developed. But the one that has gained wide acceptance and applicability is that of Besag, York and Mollie (the BYM model), which allows for both heterogeneous and spatially structured random effects 48 . For the structured spatial effect, we assume a first-order intrinsic Gaussian Markov Random Field prior 46 and two-dimensional P-spline prior ${ }^{49}$.

\section{Model estimation}

In Bayesian framework, all functions and parameters are assigned appropriate prior functions. The smooth functions and model parameters used the empirical Bayesian approach according ${ }^{50}$. The fixed effect parameters, $\beta$ of the categorical covariates assumed non-informative diffuse priors, $\mathrm{p}(\beta \mathrm{k}) \sim$ constant

The non-linear smooth functions of continuous covariate (mother's age (in years) in our case) adopt a Bayesian P-splines prior as suggested in the work of Fahmier et $\mathrm{al}^{51}$, as an extension of polynomial regression splines proposed by Elier and $\mathrm{Maxr}^{52}$. The basic assumption behind the P-splines approach is that the unknown smooth function $f$ can be approximated by a spline of degree 1 defined on a set of equally spaced knots within the domain of $\mathrm{x}$. The spline can then be written as a linear combination of basis function (B-spline), i.e. $\mathrm{f}(\mathrm{x})=\mathrm{Pj}=1 \beta \mathrm{j} \mathrm{Bj}(\mathrm{x})$ where $\mathrm{Bj}(\mathrm{x})$ are $\mathrm{B}-$ splines. Smoothness of the basis function is achieved by a first or second-order random walk model. In our case, the second-order random walk is adopted in this study i.e. $\beta \mathrm{j}=2 \mathrm{bj}-1+\mathrm{bj}-2$ with Gaussian error $\beta$ $\sim \mathrm{N}\left(0, \tau^{2}\right)$.

Multivariate conditional auto-regressive(MCAR) Prior

The development of the multivariate model is credited to 55 , which is an extension of Besag ${ }^{53}$ results into a multivariate setting. In their work, Mardia 55 showed that conditions under which the conditional multivariate distribution uniquely determines the corresponding multivariate joint probability density function.

Under this condition, ${ }^{54}$ extended MCAR into a generalized MCAR model in the following manner. Let $\Phi=\left(\phi_{1}^{T}, \phi_{2}^{T}, \ldots, \phi_{n}^{T}\right)$, where each $\varphi \mathrm{i}$ is $\mathrm{n} \times 1$ vector. Then $\Phi$ is an $n p \times 1$ vector. Also let $\Phi$ have a multivariate Gaussian distribution with mean, 0 and dispersion matrix 
Q, we then define

$$
p(\bullet)-\langle 2 v)^{\mp}|Q| \exp \left\{\frac{1}{2} \boldsymbol{t}^{z}(\underline{\phi}\}\right.
$$

$\mathrm{Q}$ is an $\mathrm{np} \times \mathrm{np}$ symmetric and positive definite matrix. It is informative to look at $\mathrm{Q}$ as a $\mathrm{p} \times \mathrm{p}$ block matrix with $\mathrm{n} \times \mathrm{n}$ block Qij and the full conditional distributions are then given by

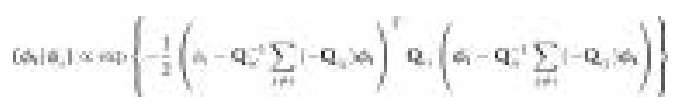

This implies that and the full conditional probability density function is given by

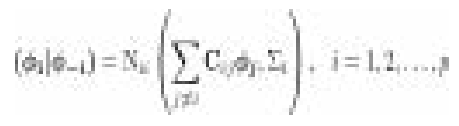

where $\Sigma \mathrm{i}$ and $\mathrm{Cij}$ are $\mathrm{n} \times \mathrm{n}$ matrices analogues to oij and cij as defined for the univariate case above (6). The matrix $\sum$ iis also symmetric and positive definite. the matrices $\sum \mathrm{i}$ and Cij can also be written in terms of $\mathrm{Q}$, the precision matrix of the joint distribution as $C$ and. If we set $\Sigma$ to be a block diagonal matrix with $\Sigma \mathrm{i}$ blocks and $\mathrm{C}$ as a partitioned matrix with blocks $C_{i j}$ and $\mathrm{Cij}=0 \mathrm{n} \times \mathrm{n}$, then $\mathrm{Q}=\Sigma^{-1}(\mathrm{I}-\mathrm{C})$

A propriety parameter, $\alpha$ can be added into the precision matrix into equation (12) to yield

$$
\mathrm{Q}=\Sigma-1(\mathrm{I}-\alpha \mathrm{C})
$$

For a symmetric matrix $\mathrm{Q}$ and smoothing parameter $\alpha$ satisfying the condition such that $\mathrm{Cij} \sum \mathrm{j}=\sum \mathrm{iCT}$, 56 denoted the distribution by $\operatorname{MCAR}(\mathrm{C}, \Sigma)$. To carry out the inference, $\alpha$ and $\Sigma$ are assigned appropriate priors, such as uniform distribution for $\alpha$ and Wishart $(\varrho, \Sigma 0)$ for $\Sigma$.

\section{Posterior computation}

The joint posterior distribution for the spatial bilogit model is given by $\pi(\beta 1, \beta 2, \alpha 1, \alpha 2, \varrho, \Phi, \Sigma) \propto$

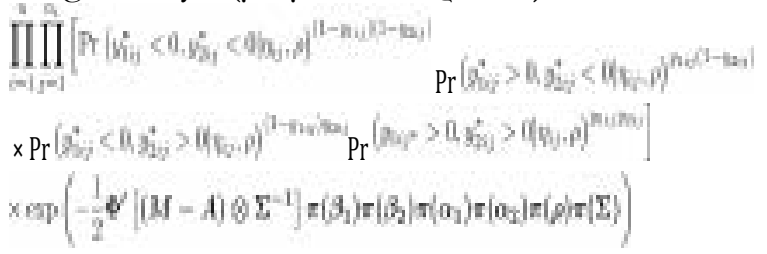

where $\eta \mathrm{ij}=(\eta 1 \mathrm{ij}, \eta 2 \mathrm{ij} 0)$ as given in equation (4) and the $\pi($.$) represent the prior distributions for their respective$ parameters as defined in section above.

The model performances are investigated via deviance information criterion (DIC) $57, \mathrm{DIC}=\mathrm{D}(\theta)+\mathrm{pD}$ is a model selection criterion according to which the model performance is evaluated as the sum of a measure of fit, the posterior mean of the deviance, $\mathrm{D}=\mathrm{E}-2 \log (\mathrm{f}(\mathrm{y} \mid \mathrm{pa}-$ rameters)), and a measure of complexity, the effective number of parameters, $\mathrm{pD}$ is obtained as the diference between the deviance posterior mean and the deviance evaluated at the parameters posterior mean. Thus, a model is preferred if it shows a lower DIC value.

\section{Data analysis}

The above-discussed models were applied on data obtained from DHS of Burkina faso 2010 and Mozambique 2011. The first part of the analysis consists was carried out using independent univariate models. Of which the results produced three outputs namely Tables of posterior estimates of fixed effects, spatial maps and non-linear graphs. The second part consists of results from multivariate analysis. using the Multivariate CAR model analysis in section and implemented in WinBUGS 14.

\section{Study population}

The tabulated number of the children suffering from undernutrition in the sampled population by country are presented in Table 1. The overall prevalence of childhood anemia among the children understudy in the two countries are similar with about $30.9 \%$ of the regions showed high prevalence in both countries (Burkina Faso and Mozambique). The wasting prevalence in Burkina Faso was $15.5 \%$, which was about 3 times higher than prevalence in Mozambique (5.5\%). But percentage of stunting was slightly higher among Mozambican children (42.6 percent) to that of Burkina Faso, 34.8 percent. From survey population, there were many missing values, may be the respondent (mother) declined to provide information about her child, or the child was not available (not at home) when the interview was being conducted, or the child was sick, or the child was living with a family relation. 
Table 1: Percentage distribution of child's health conditions (stunting, wasting and anemia) by country in total sampled population from the Demographic and Health Surveys.

\begin{tabular}{lllllll}
\hline Country & Years of DHS & $\begin{array}{l}\text { Population } \\
\text { sample(N) }\end{array}$ & No of children & No of stunted & No of wasted & No of anemic \\
& & 15044 & 6994 & children(\%) & children (\%) & children (\%) \\
\hline Burkina Faso & 2010 & 11102 & 10313 & $4320(34.8)$ & $1084(15.5)$ & $2343(30.9)$ \\
Mozambique & 2011 & & & $4393(42.6)$ & $609(5.9)$ & $3394(30.9)$ \\
\hline
\end{tabular}

$\%=$ ratio of number of cases children divided by sample population at risk (response)

The exploratory variables considered in the analysis are based on the existing literature on the socio-demographic determinants of the under nutrition indicators / variables. About 81 percent of these children were from rural areas, of which there was higher prevalence stunting among the children than the urban. About one-half of the children (54\%) were either first-born or at second and third order. While the percentage prevalence of anemia had a linear association with birth order, childhood stunting and wasting did not indicate any consistent linear association with the birth order. Majority of these children (97\%) were born of single birth, with higher prevalence of anemia and stunting were $25.9 \%$ and $39.1 \%$ respectively among children of multiple birth (twin) than the single birth $(22.9 \%$ and $28.2 \%)$, but lower prevalence of child wasting. About a quarter of these children were born to mothers who attained no formal education $(25.5 \%)$, some formal education $(63.3 \%)$ attained primary, while $11.3 \%$ achieved secondary or higher). Generally, the prevalence percentage $n$ of anemia did not differ significantly among the maternal wealth strata(groups), but the prevalence of childhood malnutrition (stunting and wasting) decline linearly as the maternal wealth move upward the economic strata.

\section{Model comparison}

Table 2 presents the measure of fitness using Deviance Information Criteria(DIC) from univariate analysis for malnutrition indicators among under five children in Burkina Faso and Mozambique. Model M2 showed a substantial difference $(\triangle \mathrm{DIC})$ over model M1 within the range of 50 and 150 . For each country, we provide the goodness of fit values for each type of child malnutrition. The best model selected has the lowest DIC. BYM model(M2) is considered the best models overall because they yielded the smallest DIC values. The inference revealed that the spatial random effects had significant determinant factors that influence prevalence of childhood malnutrition.

Geographical prevalence of childhood anemia, stunting and wasting

Table 2: Deviance Information Criterion (DIC) for the measure goodness of fit for the independent univariate analysis

\begin{tabular}{|c|c|c|c|c|c|c|}
\hline \multirow[t]{2}{*}{ Model } & \multicolumn{3}{|c|}{ Burkina Faso } & \multicolumn{3}{|c|}{ Mozambique } \\
\hline & $D(\theta)$ & $\mathrm{pD}$ & DIC & $D(\theta)$ & $\mathrm{pD}$ & DIC \\
\hline \multicolumn{7}{|c|}{ Anemia } \\
\hline M1 & 9237.85 & 23.96 & 9261.81 & 13461.00 & 24.00 & 13485.00 \\
\hline M2 & 9087.00 & 36.20 & 9123.20 & 13334.39 & 34.67 & 13369.06 \\
\hline \multicolumn{7}{|c|}{ Stunting } \\
\hline M1 & 7368.49 & 23.94 & 7392.43 & 11047.37 & 23.98 & 11071.35 \\
\hline M2 & 7330.59 & 33.98 & 7364.57 & 10891.00 & 35.30 & 10926.30 \\
\hline \multicolumn{7}{|c|}{ Wasting } \\
\hline M1 & 4909.40 & 23.86 & 4933.26 & 3176.17 & 23.69 & 3199.86 \\
\hline M2 & 4845.18 & 34.47 & 4879.65 & 3113.24 & 32.59 & 3145.83 \\
\hline
\end{tabular}




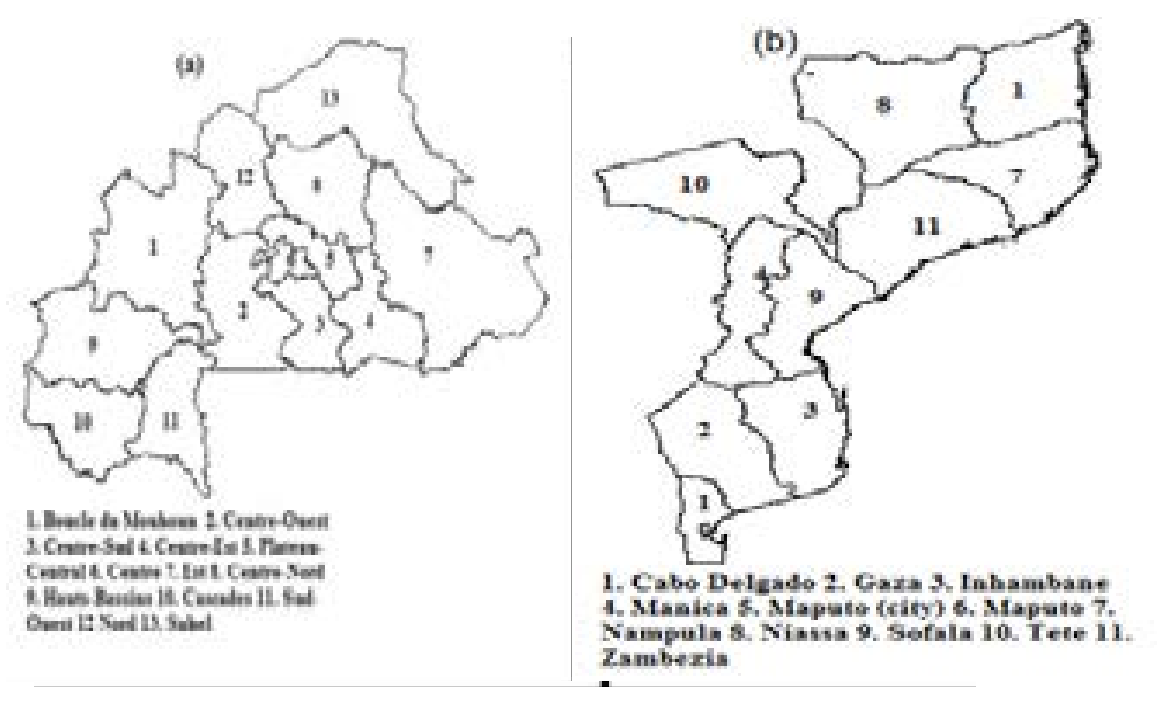

Figure 1: Maps showing geographical regions/ provinces in (a) Burkina Faso (b) Mozambique

Figure 2 presents a set of maps of the estimated smooth geographical effects on malnutrition prevalence among children in Burkina Faso, after controlling for other covariates. It was evident that there were apparent geographical disparities across sub-national level or province level as seen from the graphics. The spatial residual effects are grouped into five categories with black coloured region signifying the lowest spatial residuals and a yellow coloured region denotes highest risk. Burkina Faso: From spatial plots displayed in Fig 2, it could be observed that children living in about 15\% geographical (2 regions) areas were found to experience high prevalence for anemia 2, whereas 23 percent and 46 percent of these regions showed high prevalence for stunting and wasting respec- tively. Sahel and Cascades were two regions with high prevalent of anemia e, but only Sahel region also showed high prevalence from all the malnutrition indicators. Three regions (Sahel, Est and Cascades) had high risk of childhood stunted only, while four (4) regions (Centre-Nord and Centre Sud) constituting 30\% of higher risk wasted regions. Two regions (Hauts-Bassins and SudOuest) had low prevalence of being anemia and wasting, while Centre-Ouest and Boucle du Mounhoun regions recorded low risk of stunting. A further inspection of the maps indicated that Est region was only region experienced high risk of both stunting and wasting. Cascades region experienced high prevalence for both anemia and stunting, but the Sud-Oest and Hauslts-Bassins regions recorded low prevalence for anemia, but not wasting.
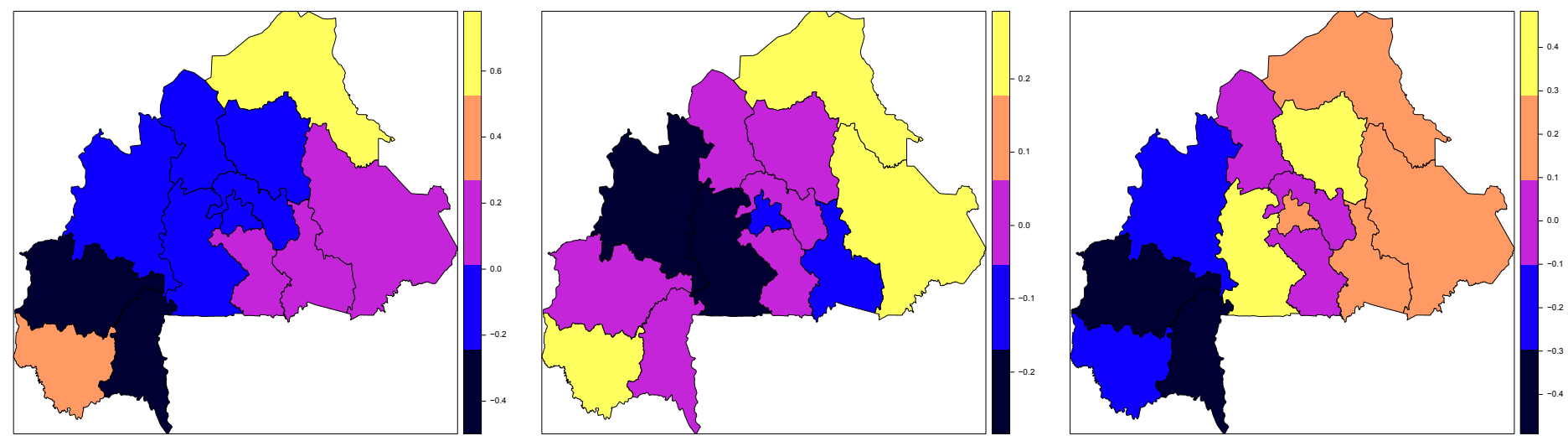

Figure 2: Mapping of posterior mean of structured spatial residual effect of childhood

(a)anemia, (b)stunting and (c) wasting showing posterior mean of prevalence in Burkina Faso, DHS2010 
Mozambique: carefully inspection of the maps of the spatial residual plots displayed in Figure 3, about 65\% of the provinces in Mozambique were classified to be high prevalence for anemia among young children living in seven provinces (Niassa, Nampula, Tete, Maniza, Gaza, Sofala and Zambezia). Furthermore, three provinces (Cabo, Delgado, and Gaza) recorded high prevalence of childhood stunting, and four other provinces predicted with high prevalence of childhood wasting. For instance, anemia and wasting prevalence exhibit co-occurrence across the two provinces of Manica and Nampula, but only Gaza province classified with high prevalence for both anemia and stunting among the children, while Maputo and Maputo city had a high prevalence both stunted and wasted. The maps generally revealed a higher prevalent of stunting and wasting occupying in about $35 \%$ and $37 \%$ of the provinces but 4 provinces high anemia plus Maputo city .
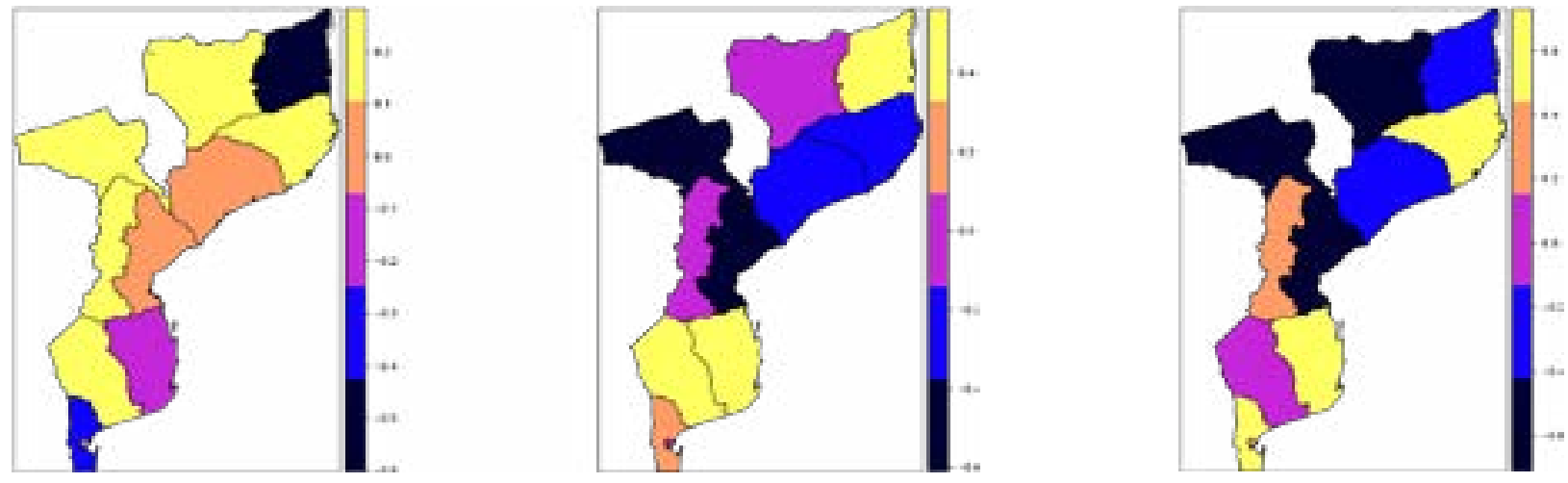

Fig 3. Mapping of posterior mean of structured spatial residual effect of childhood (a)anemia, (b)stunted and (c) wasted showing posterior mean of prevalence in Mozambique DHS 2011.

\section{Non-linear effects of mother's age on the childhood under nutrition}

The mother's age of the model is described by the non-linear functional relationship on the malnutrition status, i.e. the effect of mother "s age "mage" on the child malnutrition indicators. The graphs depict that it cannot be represented linear functions. Fig. 4 a represents the effect of mother 's age on the childhood anemia, and it describes a non-linear relationship resemble a flip S-shape curve or reversed sigmoid curve of the mother's age at birth on the anemia risk among children in Burkina Faso. The graph can be segmented into three phases:(underage mother (teenage, $\leq 20$ years) mothers, young mother (20 - 32 years) represented by 'plateau' or stabilize, and older mother ( $\geq 32$ years). This translates into the risk of anemia declines at a slow rate among children of young mothers and flexes at age say, between $20-30$ years, and soon after 30 years, the anemia risk declines faster. Fig. $4 \mathrm{~b}$ described the relationship between the mother 's age (years) effects and child' stunting can be described as a U-shape curve or J-shape function, as displayed in Fig 4b. This indicates that a reduced risk of anemia in children whose mother's age was less than 28 years old and then rose exponentially. Fig. $4 \mathrm{~b}$ refer to stunting prevalence in Burkina Faso: Fig. describes the relationship between mother's age and children risk of stunting was a reverse sigmoid-curve and it resembles the effect of anemia risk as for Burkina Faso, but it declines at a slower rate. Whereas the Figure $4 \mathrm{c}$ shows that the relationship between the mother 's age and childhood wasting was a power law curve or downward- concave curve, indicative that the wasted risk decreases faster among the children of older mothers (say, $\geq 30$ years) than of younger and teenage mothers in Burkina Faso. 

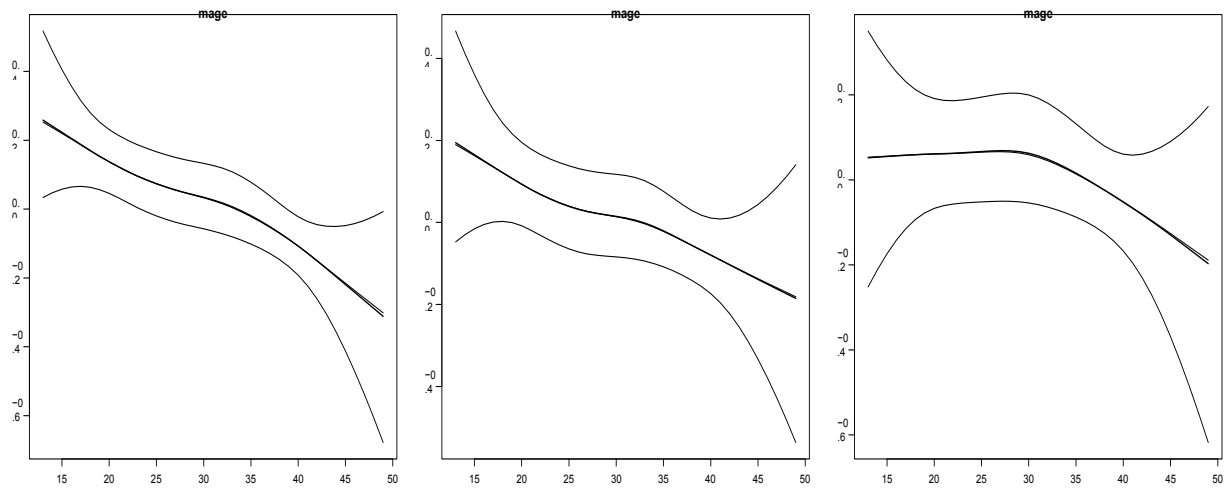

Figure 4: Non-linear plot of the effect of mother 's age(years) on (a) anemia, b) stunting and c) wasting showing posterior mean and $95 \%$ credible interval for Burkina Faso data. In all tests, the mother's age (in years) along the horizontal axis, and relative posterior risk effect on the vertical axis.

Mozambique: Figure 5a described the effect of mother's age (in years) at birth and child anemia risk. The relationship represents a non-linear relation such like a flipped $S-$ shape curve, indicating a small rise of anemia risk in children born of teenage mothers (less 20 years) and the risk decreases soon after until mother's age 40 and rise again. The lowest prediction of the anemia risk in Mo- zambican children can be attained at the mother's age of 40 years old. Figure $5 \mathrm{~b}$ describes the effect of mother 's age (years)and the child risk of stunting, which can be illustrated to be an inverse J-shape (or truncated exponential function), while the effect on childhood wasting could be described as a power-law function with a constant exponent scaling factor or concave down curve as displayed by Figure $5 \mathrm{c}$.
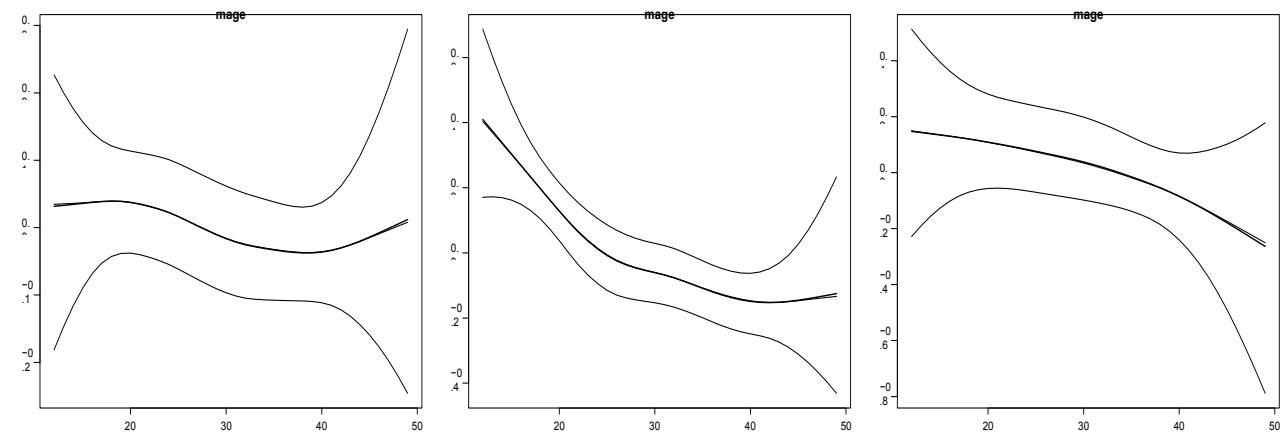

Figure 5: Non-linear plot of the effect of mother 's age(years) on (a) anemia, (b) stunting and c) wasting showing posterior mean and $95 \%$ credible interval for Mozambique data. In all tests, the mother's age (in years) along the horizontal axis, and relative posterior risk effect on the vertical axis. 


\section{Fixed effects estimates of categorical covariates}

Tables presented the results of the fixed-effects parameter estimates are based on Model 2. The relative contribution of each risk factor to anemia was estimated from prevalence odd ratios (POR) derived from geo-additive binomial regression models with anemia as the outcome. In this section, we present the fixed effect estimates of the covariates considered to be categorical in the models and the corresponding 95\% credible intervals on the three child 's health conditions. The interpretation of the binomial response models was done using its odds and corresponding 95\% credible intervals. Generally, whenever the odds confidence interval includes one, it indicates that the variable effect is statistically not significant at $95 \%$ CI.

From Table 3 for Burkina Faso, eight risk factors were found to be significantly associated with anemia. The children aged 12-24 months had strongest risk of anemia than the reference group above 2 years, with higher odds $(\mathrm{OR}=1.19 ; \mathrm{CI} 95 \% ; 1.01,1.40)$, but young infants, aged
1-5 months old had lower chance of anemic, $\mathrm{OR}=0.836$; CI 95\% (0.74 to 0.94). Also, children whose mother were literate $(\mathrm{OR}=0.84$, CI 95\%; 0.77 to 0.91$)$; (ability to read and write) had significant lower odds of being anemic compared with children of non-literate: and Mozambique $(\mathrm{OR}=0.91, \mathrm{CI} 95 \% ; 0.85$ to 0.95$)$. In addition, children living in families that belonged to a higher wealth index quintile were at a lower risk of anemia: 0.90; 95\% CI, $0.81-1.00)$ for richer household, and lowest anemia risk in richest household; $\mathrm{OR}=0.87, \mathrm{CI} 95 \% ; 0.72$. to 1.03 ), but not significant. Children who experienced morbidity ( 2 weeks before the survey) were at a higher risk of anemia, particularly pneumonia and fever had contributed to a larger anemia risk, although they were not statistically significant. For instance, Burkina Faso children who had diarrhea had significant increased risk of stunting: 1.230; $95 \% \mathrm{CI}(1.047,1.443)$ and wasting 1.327 ; 95\%CI (1.095, 1.605) wasting. Children whose mothers took iron syrup supplementation during pregnancy were 2.5 times more likely to be anemic. In other words, children whose mothers took iron/syrup supplementation during pregnancy raise its anemia risk by $145 \%, \mathrm{OR}=2.25$, CI $(1.42,4.21)$.

Table 3: Posterior odd ratios and 95\% credible intervals of fixed effect risk factors for anemia, stunting and wasting among under-five children in Burkina Faso (BDHS2010)

\begin{tabular}{|c|c|c|c|c|c|c|}
\hline \multirow[b]{2}{*}{ variables } & \multicolumn{2}{|r|}{ stunting } & \multicolumn{2}{|r|}{ wasting } & \multicolumn{2}{|r|}{ Anemia } \\
\hline & Odds & $95 \% \mathrm{CI}$ & odds & $95 \% \mathrm{CI}$ & odds & $95 \% \mathrm{CI}$ \\
\hline (Intercept) & 0.227 & $(0.177,0.289)$ & 0.068 & $(0.049,0.094)$ & 0.330 & $(0.272,0.400)$ \\
\hline $\begin{array}{l}\text { Sleeping under bednet } \\
\text { No(ref.) } \\
\text { bednet }\end{array}$ & $\begin{array}{l}1.000 \\
1.044\end{array}$ & $(0.963,1.133)$ & $\begin{array}{l}1.000 \\
0.924\end{array}$ & $(0.832,1.026)$ & $\begin{array}{l}1.000 \\
0.963\end{array}$ & $(0.896,1.036)$ \\
\hline $\begin{array}{l}\text { Child age(months) } \\
1-5 \\
6-11 \\
12-24 \\
>24 \text { months (ref.) }\end{array}$ & $\begin{array}{l}1.872 \\
1.991 \\
0.171 \\
1.000 \\
\end{array}$ & $\begin{array}{l}(1.622,2.166) \\
(1.719,2.308) \\
(0.125,0.230)\end{array}$ & $\begin{array}{l}1.163 \\
1.770 \\
0.626 \\
1.000 \\
\end{array}$ & $\begin{array}{l}(0.990,1.365) \\
(1.508,2.077) \\
(0.483,0.806)\end{array}$ & $\begin{array}{l}1.064 \\
0.836 \\
1.193 \\
1.000 \\
\end{array}$ & $\begin{array}{l}(0.957,1.184) \\
(0.742,0.941) \\
(1.014,1.403)\end{array}$ \\
\hline $\begin{array}{l}\text { Antenatal visits } \\
\text { No } \\
1-3 \\
\geq 4 \text { (ref.) }\end{array}$ & $\begin{array}{l}0.618 \\
1.256 \\
1.000\end{array}$ & $\begin{array}{l}(0.267,1.422) \\
(0.820,1.926)\end{array}$ & $\begin{array}{l}1.646 \\
0.872 \\
1.000 \\
\end{array}$ & $\begin{array}{r}(0.448,5.954) \\
(0.454,1.686)\end{array}$ & $\begin{array}{l}3.578 \\
0.544 \\
1.000 \\
\end{array}$ & $\begin{array}{r}(1.714,7.449) \\
(0.374,0.793)\end{array}$ \\
\hline $\begin{array}{l}\begin{array}{l}\text { Place of residence } \text { Rural } \\
\text { (ref.) }\end{array} \\
\text { Urban }\end{array}$ & $\begin{array}{l}1.000 \\
0.953\end{array}$ & $(0.869,1.046)$ & $\begin{array}{l}1.000 \\
1.077\end{array}$ & $(0.957,1.210)$ & $\begin{array}{l}1.000 \\
0.921\end{array}$ & $(0.846,1.002)$ \\
\hline $\begin{array}{l}\text { Child's sex Female } \\
\text { (ref.) } \\
\text { Male }\end{array}$ & $\begin{array}{l}1.000 \\
0.906\end{array}$ & $(0.857,0.958)$ & $\begin{array}{l}1.000 \\
0.912\end{array}$ & $(0.847,0.981)$ & $\begin{array}{l}1.000 \\
0.994\end{array}$ & $(0.945,1.045)$ \\
\hline $\begin{array}{ll}\begin{array}{l}\text { Maternal } \\
\text { (ref.) }\end{array} & \text { literacy) No } \\
\text { literate } & \\
\end{array}$ & $\begin{array}{l}1.000 \\
0.936\end{array}$ & $(0.851,1.027)$ & $\begin{array}{l}1.000 \\
0.981\end{array}$ & $(0.869,1.104)$ & $\begin{array}{l}1.000 \\
0.838\end{array}$ & $(0.769,0.912)$ \\
\hline $\begin{array}{l}\text { Mother wealth index) } \\
\text { Poorest (ref.) } \\
\text { poor } \\
\text { middle } \\
\text { richer } \\
\text { richest }\end{array}$ & $\begin{array}{l}1.000 \\
1.093 \\
1.177 \\
0.985 \\
0.658 \\
\end{array}$ & $\begin{array}{l}(0.971,1.230) \\
(1.050,1.319) \\
(0.879,1.103) \\
(0.536,0.805)\end{array}$ & $\begin{array}{l}1.000 \\
1.011 \\
0.993 \\
1.043 \\
0.888 \\
\end{array}$ & $\begin{array}{l}(0.863,1.183) \\
(0.853,1.154) \\
(0.899,1.208) \\
(0.683,1.146)\end{array}$ & $\begin{array}{l}1.000 \\
1.089 \\
1.088 \\
0.901 \\
0.865\end{array}$ & $\begin{array}{r}(0.980,1.210) \\
(0.981,1.206) \\
(0.812,0.999) \\
(0.724,1.032)\end{array}$ \\
\hline 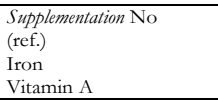 & $\begin{array}{l}1.000 \\
0.610 \\
0.955 \\
\end{array}$ & $\begin{array}{l}(0.327,1.133) \\
(0.805,1.136)\end{array}$ & $\begin{array}{l}1.000 \\
1.265 \\
1.262 \\
\end{array}$ & $\begin{array}{l}(0.479,3.301) \\
(1.014,1.585)\end{array}$ & $\begin{array}{l}1.000 \\
2.446 \\
0.988 \\
\end{array}$ & $\begin{array}{r}(1.418,4.210) \\
(0.849,1.152)\end{array}$ \\
\hline $\begin{array}{l}\text { Child spacing }(3 \text { years } \leq 1 \\
\text { child(ref.) } \\
\geq 2 \text { children) }\end{array}$ & $\begin{array}{l}1.000 \\
1.039\end{array}$ & $(0.934,1.154)$ & $\begin{array}{l}1.000 \\
1.057\end{array}$ & $(0.926,1.203)$ & $\begin{array}{l}1.000 \\
0.968\end{array}$ & $(0.888,1.054)$ \\
\hline $\begin{array}{l}\text { Breast feeding No } \\
\text { (ref.) } \\
\text { Breastfed }\end{array}$ & $\begin{array}{l}1.000 \\
1.058\end{array}$ & $(0.886,1.265)$ & $\begin{array}{l}1.000 \\
1.727\end{array}$ & $(1.376,2.177)$ & $\begin{array}{l}1.000 \\
0.697\end{array}$ & $(0.613,0.792)$ \\
\hline $\begin{array}{l}\text { Disease morbidity } \\
\text { No } \\
\text { diarrhea } \\
\text { Cough } \\
\text { fever }\end{array}$ & $\begin{array}{l}1.000 \\
1.230 \\
0.012 \\
0.916 \\
\end{array}$ & $\begin{array}{r}(1.047,1.443) \\
(0.000,48.790) \\
(0.790,1.062)\end{array}$ & $\begin{array}{l}1.000 \\
1.327 \\
2.472 \\
1.210 \\
\end{array}$ & $\begin{array}{l}(1.095,1.605) \\
(0.380,12.52) \\
(1.006,1.453)\end{array}$ & $\begin{array}{l}1.000 \\
0.949 \\
0.931 \\
1.108 \\
\end{array}$ & $\begin{array}{l}(0.811,1.110) \\
(0.160,4.106) \\
(0.962,1.274)\end{array}$ \\
\hline $\begin{array}{l}\text { Vaccination } \\
\text { No } \\
\text { Measles vaccine. }\end{array}$ & $\begin{array}{l}1.000 \\
1.038 \\
\end{array}$ & $(0.958,1.126)$ & $\begin{array}{l}1.000 \\
0.940 \\
\end{array}$ & $(0.847,1.045)$ & $\begin{array}{l}1.000 \\
0.982 \\
\end{array}$ & $(0.913,1.057)$ \\
\hline $\begin{array}{l}\text { Access to electricity } \\
\text { No } \\
\text { Yes }\end{array}$ & $\begin{array}{l}1.000 \\
0.846 \\
\end{array}$ & $(0.719,0.993)$ & $\begin{array}{l}1.000 \\
0.907\end{array}$ & $(0.745,1.101)$ & $\begin{array}{l}1.000 \\
1.065 \\
\end{array}$ & $(0.934,1.213)$ \\
\hline
\end{tabular}


Refer to Table 4 for Mozambique, the direction of the effects of covariates were similar to that of Burkina Faso, child spacing, breastfeeding, antenatal attendance, use bed-nets, mother's literacy and children age5-11 months were associated with lower likelihood of anemia. However, younger infant 1-5 months:1.351; $95 \%$ CI $(1.211,1.508)$ had significant higher risk of anemia. Children whose mothers took iron syrup: $2.030,95 \%$ CI $(1.357,3.035)$ and did not attend antenatal class: 2.564, CI\%(1.460, 4.496) were also found to raise risk of anemia. Other factors such as disease morbidity, measles vaccination and urban residence had increased risk of anemia, but it was not statistically significant. There were slight significant differentials in gender in the malnutrition prev- alence among children in this study. Children belonging to upper socio-economic status(SES), i.e. richest: 0.705, CI95\%(0.581, 0.855) had significant lower likelihood of stunting, but not significant for wasting compared to the less economically deprived household (richer family). Children, age below 12 months (infants) were at higher risk of child malnutrition (adjusted height-for-age and weight-for-height) than the older children (over 2 years of age). Furthermore, children who had experienced disease morbidity (two weeks prior to the survey) had higher probability of being stunting, wasting or both. Mozambican children who had recent episode of disease morbidity e.g fever were significantly stunted 1.170; $(1.014,1.348)$ but not significantly wasted: 1.152 ; $95 \% \mathrm{CI}(0.851,1.544)$.

Table 4: Posterior odds ratios and 95\% credible intervals of fixed effect risk factors for anemia, stunted and wasting among under-five children in Mozambique (MDHS2011)

\begin{tabular}{|c|c|c|c|c|c|c|}
\hline \multirow[b]{2}{*}{ Variables } & \multicolumn{2}{|r|}{ stunting } & \multicolumn{2}{|r|}{ wasting } & \multicolumn{2}{|r|}{ Anemia } \\
\hline & Odds & $95 \% \mathrm{CI}$ & odds & $95 \% \mathrm{CI}$ & odds & $95 \% \mathrm{CI}$ \\
\hline (Intercept) & 0.318 & $(0.270,0.374)$ & 0.020 & $(0.014,0.029)$ & 0.369 & $(0.322,0.422)$ \\
\hline $\begin{array}{l}\text { Sleeping under bennet } \\
\text { No(ref.) } \\
\text { bednet }\end{array}$ & $\begin{array}{l}1.000 \\
0.994 \\
\end{array}$ & $(0.934,1.058)$ & $\begin{array}{l}1.000 \\
1.154 \\
\end{array}$ & $(1.003,1.331)$ & $\begin{array}{l}1.000 \\
0.930 \\
\end{array}$ & $(0.879,0.985)$ \\
\hline $\begin{array}{l}\text { Child age(months) } \\
1-5 \\
6-11 \\
11-24 \\
>24 \text { months (ref.) }\end{array}$ & $\begin{array}{l}1.351 \\
1.866 \\
0.298 \\
1.000\end{array}$ & $\begin{array}{l}(1.211,1.508) \\
(1.682,2.070) \\
(0.244,0.362\end{array}$ & $\begin{array}{l}0.997 \\
2.030 \\
0.936 \\
1.000\end{array}$ & $\begin{array}{l}(0.790,1.254) \\
(1.669,2.467) \\
(0.654,1.324)\end{array}$ & $\begin{array}{l}1.000 \\
0.892 \\
1.200 \\
1.000\end{array}$ & $\begin{array}{l}(0.914,1.093) \\
(0.816,0.974) \\
(1.048,1.373)\end{array}$ \\
\hline $\begin{array}{l}\text { Antenatal visits } \\
\text { No } \\
1-3 \\
\geq 4 \text { (ref.) } \\
\end{array}$ & $\begin{array}{l}1.241 \\
0.926 \\
1.000 \\
\end{array}$ & $\begin{array}{l}(0.656,2.344) \\
(0.672,1.275)\end{array}$ & $\begin{array}{l}0.983 \\
0.996 \\
1.000 \\
\end{array}$ & $\begin{array}{l}(0.183,5.153) \\
(0.433,2.313)\end{array}$ & $\begin{array}{l}2.564 \\
0.644 \\
1.000 \\
\end{array}$ & $\begin{array}{l}(1.460,4.496) \\
(0.485,0.855)\end{array}$ \\
\hline $\begin{array}{l}\text { Place of residence Rural (ref.) } \\
\text { urban }\end{array}$ & $\begin{array}{l}1.000 \\
0.994 \\
\end{array}$ & $(0.929,1.063)$ & $\begin{array}{l}1.000 \\
0.855 \\
\end{array}$ & $(0.727,1.000)$ & $\begin{array}{l}1.000 \\
1.055\end{array}$ & $(0.993,1.120)$ \\
\hline $\begin{array}{l}\text { Child's sex Female (ref.) } \\
\text { Male }\end{array}$ & $\begin{array}{l}1.000 \\
0.922\end{array}$ & $(0.881,0.965)$ & $\begin{array}{l}1.000 \\
0.902\end{array}$ & $(0.815,0.998)$ & $\begin{array}{l}1.000 \\
0.996\end{array}$ & $(0.956,1.038)$ \\
\hline $\begin{array}{l}\text { Mother literacy No (ref.) } \\
\text { literate }\end{array}$ & $\begin{array}{l}1.000 \\
0.895\end{array}$ & $(0.843,0.950)$ & $\begin{array}{l}1.000 \\
0.819\end{array}$ & $(0.711,0.941)$ & $\begin{array}{l}1.000 \\
0.905\end{array}$ & $(0.857,0.954)$ \\
\hline $\begin{array}{l}\text { Mother wealth index) } \\
\text { Poorest (ref.) } \\
\text { poor } \\
\text { middle } \\
\text { richer } \\
\text { richest }\end{array}$ & $\begin{array}{l}1.000 \\
1.133 \\
0.993 \\
0.978 \\
0.705\end{array}$ & $\begin{array}{l}(1.015,1.263) \\
(0.896,1.099) \\
(0.887,1.078) \\
(0.581,0.855)\end{array}$ & $\begin{array}{l}1.000 \\
0.913 \\
0.958 \\
0.867 \\
0.897\end{array}$ & $\begin{array}{l}(0.710,1.171) \\
(0.755,1.210) \\
(0.684,1.090) \\
(0.566,1.410)\end{array}$ & $\begin{array}{l}1.000 \\
0.926 \\
0.973 \\
0.957 \\
1.033\end{array}$ & $\begin{array}{l}(0.837,1.026) \\
(0.886,1.069) \\
(0.877,1.044) \\
(0.877,1.217)\end{array}$ \\
\hline $\begin{array}{l}\text { Mother supplementation No (ref.) } \\
\text { Iron } \\
\text { Vitamin A }\end{array}$ & $\begin{array}{l}1.000 \\
1.179 \\
0.917 \\
\end{array}$ & $\begin{array}{r}(0.748,1.857) \\
(0.842,0.999) \\
\end{array}$ & $\begin{array}{l}1.000 \\
1.417 \\
0.896 \\
\end{array}$ & $\begin{array}{r}(0.425,4.657) \\
(0.760,1.061)\end{array}$ & $\begin{array}{l}1.000 \\
2.030 \\
0.997 \\
\end{array}$ & $\begin{array}{l}(1.357,3.035) \\
(0.922,1.079) \\
\end{array}$ \\
\hline $\begin{array}{llll}\begin{array}{l}\text { Spacing(birth } \\
\text { child(ref.) }\end{array} & & & \text { years } \leq 1 \\
\geq 2 \text { children ) } & & & \\
\geq\end{array}$ & $\begin{array}{l}1.000 \\
0.977\end{array}$ & $(0.905,1.056)$ & $\begin{array}{l}1.000 \\
0.998\end{array}$ & $(0.842,1.174)$ & $\begin{array}{l}1.000 \\
0.917\end{array}$ & $(0.857,0.980)$ \\
\hline $\begin{array}{l}\text { Breast feeding } \mathrm{No} \text { (ref.) } \\
\text { Breastfed }\end{array}$ & $\begin{array}{l}1.000 \\
0.894\end{array}$ & $(0.789,1.014)$ & $\begin{array}{l}1.000 \\
1.110\end{array}$ & $(0.869,1.431)$ & $\begin{array}{l}1.000 \\
0.725\end{array}$ & $(0.660,0.797)$ \\
\hline $\begin{array}{l}\text { Disease morbidity } \\
\text { No } \\
\text { Diarrhea } \\
\text { Cough } \\
\text { fever } \\
\end{array}$ & $\begin{array}{l}1.000 \\
1.084 \\
0.258 \\
1.170\end{array}$ & $\begin{array}{l}(0.931,1.260) \\
(0.022,1.765) \\
(1.014,1.348) \\
\end{array}$ & $\begin{array}{l}1.000 \\
0.914 \\
6.709 \\
1.152 \\
\end{array}$ & $\begin{array}{l}(0.664,1.242) \\
(0.961,36.64) \\
(0.851,1.544) \\
\end{array}$ & $\begin{array}{l}1.000 \\
0.941 \\
1.200 \\
1.088\end{array}$ & $\begin{array}{l}(0.811,1.091) \\
(0.328,3.937) \\
(0.947,1.249)\end{array}$ \\
\hline $\begin{array}{l}\text { Vaccination } \\
\text { No } \\
\text { Measles vaccine. }\end{array}$ & $\begin{array}{l}1.000 \\
0.983\end{array}$ & $(0.920,1.050)$ & $\begin{array}{l}1.000 \\
1.042\end{array}$ & $(0.909,1.200)$ & $\begin{array}{l}1.000 \\
1.021\end{array}$ & $(0.961,1.085)$ \\
\hline $\begin{array}{l}\text { Access to electricity } \\
\text { No } \\
\text { electricity }\end{array}$ & $\begin{array}{l}1.000 \\
0.901\end{array}$ & $(0.817,0.994)$ & $\begin{array}{l}1.000 \\
1.127\end{array}$ & $(0.895,1.412)$ & $\begin{array}{l}1.000 \\
0.958\end{array}$ & $(0.881,1.042)$ \\
\hline
\end{tabular}


Multivariate conditional autoregressive (MCAR) analysis

The results represented in this section include the estimation of parameters from equation 4 via multivariate conditional auto-regressive (MCAR) prior in Section and implemented in WinBUGS version 14. After adjusting for the confounding factors, the covariates such as child's age(categorical), maternal wealth index (socio-economic deprivation) and birth intervals found to be significant under univariate analysis.

\section{Burkina Faso}

The posterior estimates of the covariate risk factors of the multivariate model of the three child malnutrition indicators were also presented in Table 5 for Burkina Faso.
The results revealed that all the fixed effect factors (observable) were not significantly associated with any of the malnutrition indicators considered in this study. However, refer to Table 5, the three child malnutrition indicators were significantly associated with the unobserved geographical factors in the regions.

Table 5 presents the posterior estimates of the multivariate conditional association between the childhood malnutrition prevalence with the regions in Burkina Faso. Child malnutrition prevalence was significant associated with the region if the $95 \%$ credible interval does not include zero. The overall childhood malnutrition indicators estimates showed that there were significant strong provincial associations between the regions in Burkina Faso.

Table 5: Posterior estimates and $95 \%$ credible intervals of multivariate conditional association between childhood malnutrition indicators and regions parameters among under-five children in Burkina Faso

\begin{tabular}{|c|c|c|c|c|c|c|c|c|}
\hline \multirow{3}{*}{$\begin{array}{l}\text { variables } \\
\text { intercept }\end{array}$} & \multirow[b]{2}{*}{ parameters } & \multicolumn{3}{|c|}{ Stunting } & \multicolumn{2}{|c|}{ Wasting } & \multirow{2}{*}{\multicolumn{2}{|c|}{\begin{tabular}{|l|} 
Anemia \\
$2.50 \% 97.50 \%$
\end{tabular}}} \\
\hline & & mean & \multicolumn{2}{|l|}{$\begin{array}{l}2.50 \% \\
97.50 \%\end{array}$} & $\begin{array}{l}\text { mean } \\
97.50 \% \\
\end{array}$ & $2.50 \%$ mean & & \\
\hline & $a$ & -2.074 & -199.5 & 199.8 & 2.159 & -208.6197 .3 & 0.437 & 6192.3 \\
\hline $1-5$ months & $\beta 1$ & 1.471 & -195.2 & 196.0 & 1.301 & -196.4175 .0 & 2.529 & 4196.6 \\
\hline $6-11$ & $\beta 2$ & -0.047 & -194.9 & 191.3 & -7.222 & -199.5 187.8 & 0.006 & 4192.8 \\
\hline $12-24$ & $\beta 3$ & 1.543 & -194.8 & 198.3 & -3.824 & -208.3203 .0 & 2.372 & 4200.5 \\
\hline $24-36$ & $\beta 4$ & -0.168 & -191.6 & 189.6 & 0.428 & $\begin{array}{ll}-214.6 & 200.1\end{array}$ & $-0.396 \quad-194$ & . 0193.3 \\
\hline poorest & $\beta 5$ & -0.913 & -191.4 & 193.9 & 2.334 & $\begin{array}{ll}-186.1 & 205.7\end{array}$ & $-1.088-193$ & 0190.5 \\
\hline poor & $\beta 6$ & 1.762 & -200.0 & 197.1 & -2.205 & -196.2191 .1 & $1.328-190$ & 6198.1 \\
\hline middle & $\beta 7$ & -1.513 & -187.4 & 194.4 & 2.248 & $\begin{array}{ll}-197.0 & 199.7\end{array}$ & $-1.094-195$ & 7197.5 \\
\hline richer & $\beta 8$ & -0.835 & -194.6 & 190.8 & -0.774 & -191.6 198.2 & 1.257 & 2200.0 \\
\hline$\geq 2$ children & $\beta 9$ & 0.417 & -195.9 & 199.4 & 0.733 & -185.1191 .9 & $-0.551-195$ & 0190.8 \\
\hline \multicolumn{9}{|l|}{ Regions } \\
\hline $\begin{array}{ll}\text { Boucle } & \text { de } \\
\text { Mouhoun } & \end{array}$ & $\varphi 1$ & 2179 & 2150 & 2199 & -367.1 & $-373.6-363.6$ & $\begin{array}{ll}-790.9 & -875\end{array}$ & $6-502.0$ \\
\hline Cascades & $\varphi 2$ & 3953 & 3898 & 3969 & -661.8 & $-670.2-657.5$ & $-1444.0-1569$. & $0-909.2$ \\
\hline Centre & $\varphi 3$ & 5686 & 5666 & 5720 & -949.1 & $-957.3-938.9$ & $\begin{array}{ll}-2213.0 & -2 \\
2070.0\end{array}$ & 393.0 \\
\hline Centre-Est & $\varphi 4$ & -2621 & -2662 & -2609 & 441.3 & 437.8454 .9 & 953.2618 .91 & 037.0 \\
\hline Centre-Nord & $\varphi 5$ & 4362 & 4346 & 4378 & -731.5 & $-748.0-727.8$ & $\begin{array}{ll}-1643.0 \\
1426.0\end{array}$ & 27.0 \\
\hline Centre-Ouest & $\varphi 6$ & -564.4 & -597.3 & -494.2 & 91.44 & 86.7197 .93 & $210.0-111.0$ & 307.8 \\
\hline Centre-Sud & $\varphi 7$ & -870.5 & -883.5 & -828.3 & 144.1 & 134.0160 .1 & 362.175 .10 & 698.7 \\
\hline Est & $\varphi 8$ & -5412 & -5464 & -5396 & 910.9 & 906.3924 .4 & 2005.01626 .0 & 2088.0 \\
\hline Hauts Basins & $\varphi 9$ & -3748 & -3786 & -3722 & 629.5 & 624.3631 .8 & 1415.01153 .0 & 1544.0 \\
\hline Nord & $\varphi 10$ & 3046 & 3027 & 3096 & -511.6 & $-524.7-506.3$ & $\begin{array}{l}-1132.0 \\
1195.0\end{array}$ & - -920.7 \\
\hline Plateau Central & $\varphi 11$ & 2988 & 2961 & 2999 & -503.4 & $-505.1-499.7$ & $\begin{array}{l}-1107.0 \\
1184.0\end{array}$ & --880.6 \\
\hline Sahel & $\varphi 12$ & -4080 & -4097 & -4059 & 685.8 & 683.1692 .4 & 1506.01055 .0 & 1588.0 \\
\hline Sud-Ouest & $\varphi 13$ & -4917 & -4987 & -4905 & 821.5 & 813.5838 .0 & 1879.01505 .0 & 2017.0 \\
\hline variability & $\begin{array}{l}\sigma u 21 \\
\sigma u 22 \\
\sigma u 23\end{array}$ & $\begin{array}{l}0.7549 \\
-- \\
--\end{array}$ & $(0.4693$ & \begin{tabular}{l|}
$1.264)$ \\
- \\
-
\end{tabular} & $\begin{array}{r}0.9197 \\
-\end{array}$ & (0.535 1.591) & $0.7335(0.460$ & $61.214)$ \\
\hline Correlation & $\begin{array}{l}\varrho 12 \\
\varrho 13 \\
\varrho 23\end{array}$ & $\begin{array}{r}0.184 \\
-0.038 \\
-0.037 \\
\end{array}$ & $\begin{array}{l}(-0.475 \\
(-0.621 \\
(-0.650\end{array}$ & \begin{tabular}{l|}
$0.728)$ \\
$0.582)$ \\
$0.595)$
\end{tabular} & & & & \\
\hline
\end{tabular}


Out of 13 regions in Burkina Faso, six regions were found for high risk stunting and seven regions recorded significant low prevalence. Regions with high risk stunting are: Boucle de Mouhoun, Cascades, Centre, Nord and Plateau Central. In contrast, childhood wasting and anemia were significantly low in those regions observed with high prevalence of stunting. Surprisingly, the results revealed that wasting and anemia recorded significant high prevalence in those regions with low stunting incidence. Seven regions were found with high childhood wasting and anemia prevalence are: Centre-Est, Centre-Ouest, Centre-Sud, Est, Hauts Basins, Sahel and Sud-Ouest. There were strong negative correlation between stunting and wasting; $-0.998 ; \quad 95 \%$ CI $(-1.000,-0.984)$, and a perfect negative correlation between stunting and anemia, $\varrho 1,3=$ -1 , but a significant positive correlation between wasting and anemia i.e. $0.997 ; 95 \%$ CI (0.9778 to 1.0000$)$. The positive correlation depicts the indication of co-vary in the spatial prevalent across regions, and a negative correlation indicates difference or dissimilarity in spatial patterns of prevalence.

\section{Mozambique}

In Mozambique, the results of multivariate analysis were presented in Table 6. The multivariate analysis revealed that three provinces of experienced high stunting prevalence among the children in Niassa, Tete, and Sofala), while significant low stunting prevalence in five provinces
(Cabo delgado, Nampula, Zambezia, Gaza and Maputo provincial). A significant high prevalence of childhood wasting was detected in Niassa, Tete, Manica, and Sofala. Five provinces were found to be significantly high prevalence of anemia (Niassa, Cabo Delgado, Zambezia, Maputo provincia and Maputo cicada). In addition, Table 6 also included spatial correlation estimates and the regional variability of the individual prevalence. There was a strong positive correlation between stunting and wasting; 0.986; $(0.899,1.000)$, which was significant at 95\% CI. We found that there was significant negative correlation between stunting and anemia: $-0.720,(-0.934,-0.308)$ and between wasting and anemia: $-0.640 ;(-0.903,-0.174)$.

The results further indicated that the geographical pattern of variations in the prevalence of stunting: 1427 (913.6, 2268), wasting: $1751(1117,2803)$ and anemia 556 (279.5, 978.9) were significant across the provinces in Mozambique. The findings further indicated that there was significant high prevalence of stunting among young infants age less than 1 year (age groups $1-5$ and $6-11$ months and among children of most economically deprived and deprived mothers, when compared with the reference groups. But, a significant reduction in stunting prevalence of was found among the older children age 2 years and above. In contrary, childhood wasting was less prevalence among the younger children, but older children age $12-$ 24 months had 5.3 times more likely to suffer from high risk wasting compared to children over 3 years of age. 
Table 6: Posterior estimates and 95\% credible intervals of multivariate conditional association between childhood malnutrition indicators and provinces (regions) among under-five children in Mozambique

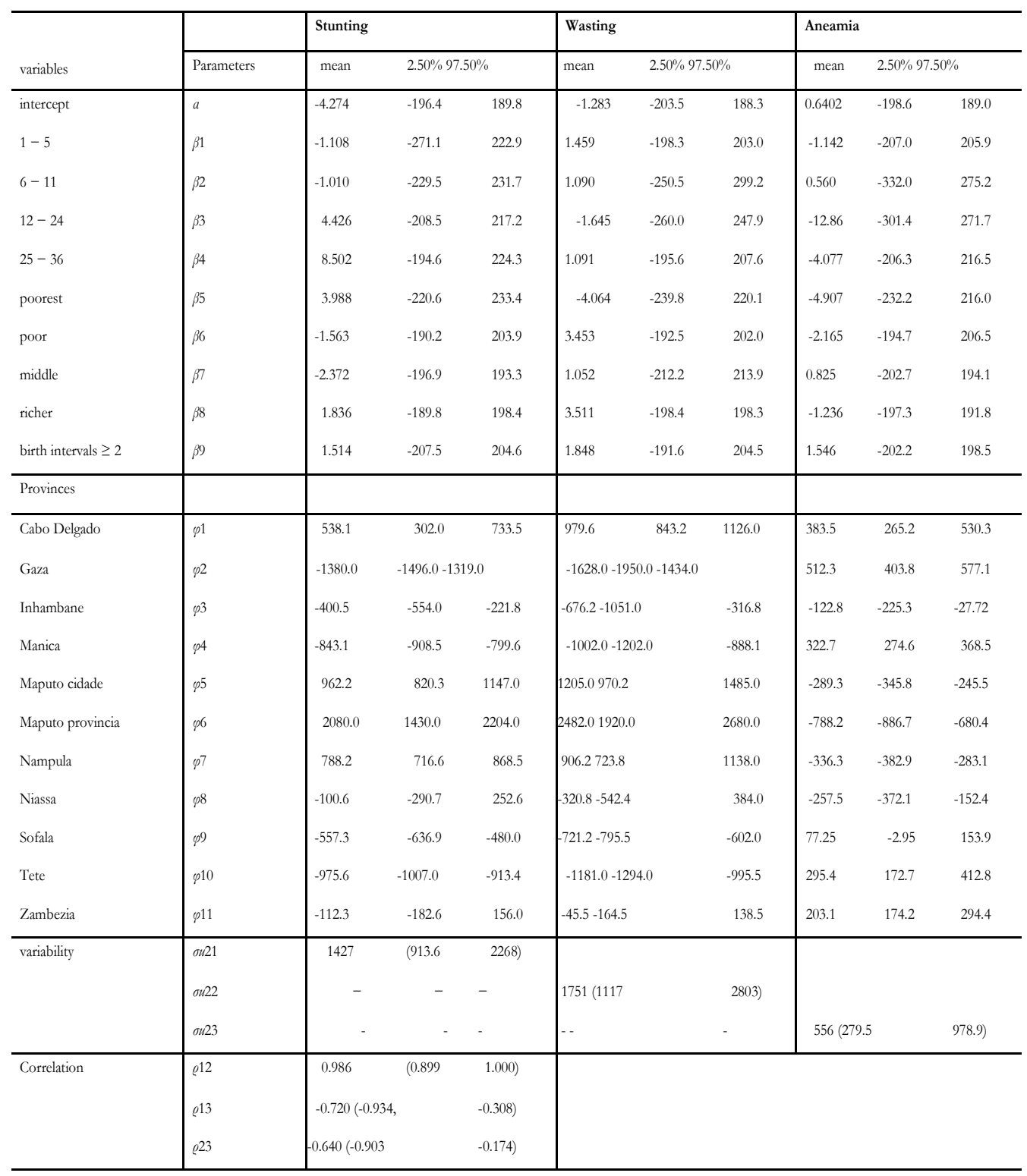

\section{Discussion}

In the present study, the research has investigated the risk factors and small-area geographical variations of child's health outcomes in sub-Saharan Africa. The study employed a flexible and robust approach, which accommodates different kinds of covariates and produce three types of output: posterior estimates of risk factors in Tables, non-linear graph of continuous covariates and spatial maps.

The present study indicated that the child and maternal characteristics are significantly associated with child mal- nutrition (including micro-nutrient anemia. The mother's characteristics such as short birth interval (less 18 months) influenced high risk of stunting and wasting but not significant among Burkina Faso children, but resulted into significantly lower prevalence of child malnutrition among Mozambican children. The effect of mother's age on the childhood malnutrition resulted into nonlinear relationship in the two countries. The children of mothers, who did not attend antenatal session were at higher risk of malnutrition compared to those whose mothers attended. The findings are in agreement with the study conducted 
in Bangladesh, which showed that previous birth interval, size at birth, mother body mass index and mother' education are significantly associated with malnutrition in under-five children ${ }^{58}$. Proceeding birth intervals have been found to be significantly correlated with childhood mortality and nutritional status in previous studies conducted many developing countries ${ }^{59},{ }^{60}$.

Additionally, the study revealed that children from wealthy households were at reduced risk of anemia and undernutrition than the material deprived households. This report was consistent with the studies conducted in other parts of sub-Saharan Africa. A study in Rwanda had elucidated that children from the lower socio-economic SES class (measured by education status, occupation) were found to be associated with higher risk of anemia, malaria infection and under nutrition ${ }^{61}$. Our findings corroborated previous results obtained in Ghana that indicated malnutrition prevalence was higher among children from the poorest SES households as much as twice as the counterparts from the richest households ${ }^{62,63}$. A study conducted in Brazil has found determinant factors such like the poorer households, inadequate nutritional food intake, poor sanitary system, lack of portable drinking water, and infectious diseases aggravate the risk of anemia in young children $^{64}$.

The result of the present study revealed that the severity of anemia decreased among the older children (i.e. as older age groups). Research evidence has shown that varying child's age determines the red blood hemoglobin requirements for physical, psychomotor functioning and cognitive developments in children in their early years of life ${ }^{65}$. This finding corroborated similar studies in SSA that malnutrition was also found to be more prevalent in older than in younger children ${ }^{66,67}$.

The results demonstrated that infants aged 6-11 months were at lower risk of anemia, perhaps this age group has adjusted to the environmental factors and breast feeding. Not surprising that the result revealed a relative high risk of anemia among age group of younger infants (age 1-5 months) and highest risk of anemia among the age group 12-23 months. Although, studies have shown that childhood anemia was rarely investigated or measured in infants aged below six months in practice, the high anemia detected among young infants (age 1-5 months) could probably be associated with child bearing mothers suffered anemia during pregnancy in those countries under- study. In contrast, the high prevalence of anemia is commonly observed among children of risk group of malaria than the same age groups of non-endemic settings $\mathrm{s}^{5,68,69}$.

In addition, the findings also revealed some factors showed non-linear relationship or curve-like association with child malnutrition status. The S-shaped growth curve (sigmoid growth curve) presents a pattern of growth in which, in a new environment, the population density of an organism increases slowly initially, in a positive acceleration phase; then increases rapidly and approaches an exponential growth rate as in the J-shaped curve; but then declines in a negative acceleration phase until at zero growth rate the population stabilizes, see for explanation ${ }^{70}$. In medicine, U-shaped risk curves have been found for risk factors such as cholesterol level, diastolic blood pressure, work stress, and alcohol use. Of these factors, the alleged U-shape relationship between alcohol use and disease risk has been the most controversial ${ }^{71}$. The graph highlights critical points or contours on the curve that are important to the health professionals. The graphs would assist the policy makers and health practitioners to monitor critical point on the curve for policy health intervention as unique feature portray for individual country.

The spatial distribution of anemia and child growth failure among young children in these countries understudy are presented as smooth maps. This demonstrated the merit of the proposed approach. The output corroborated the findings in similar studies conducted on min the sub-Saharan Africa. For example, a model-based geostatistics was used to map the risk of anemia, malaria and helminth infection in three West Africa countries ${ }^{15}$ and found that anemia in these countries (Burkina Faso, Ghana and Mali) accounted for about 37\% anemia cases in preschool children, which could be averted by treating malnutrition and malaria related infections ${ }^{15}$. Other researchers had used Bayesian geostatistical prediction in West Africa to estimate local variations in Schistosoma haematobium infection ${ }^{72}$, where high risk of S. haematobium infections was detected in the north-western part of Niger River valley of the Niger. Studies found a clustered high-intensity infection in western and central Mali, and North-eastern of Burkina Faso. A recent study conducted on childhood under nutrition in three sub-Saharan African countries ${ }^{73}$ detected a high pattern of childhood malnutrition in eastern and north-eastern 
Zambia, central Malawi and southern Tanzania. Other useful applications of multivariate mapping models has been discussed in previous studies. For example, Kinyoki et $\mathrm{al}^{34}$ recently used the multivariate approach for modeling the ecological co-morbidity of childhood diseases in Somalia. Assun applied multi-variate model to study multiple cancer site incidence. ${ }^{39}$

The result of this work would consolidate the applicability and usefulness of multivariate mapping methods for outperforming than the separate independent analysis. The present study has applied multivariate joint modeling and demonstrated the strength of method to determine the conditional correlation among malnutrition indicators and co-occurrence with the regions. The approach facilitates the computation of the spatial conditional correlation between the malnutrition indicators and the marginal variations of the geographical variation in the prevalence across the regions. The findings further identified potential socio-demographic risk factors of the three childhood malnutrition, which can be used to target specific interventions and even combination of inventions. This output could aid policy makers to design a combination of multiple strategies to optimize the scarce health resources in a more effective manner.

\section{Conclusion}

The central point of the present study was to jointly analyze three malnutrition indicator in children less than five years simultaneously. The findings provide reasonable patterns in the co-occurrence in geographic prevalence across regions. The Bayesian multivariate model adopted provides a flexible and robust tool to assess the risk factors in a unified regression model. The proposed method facilitates the estimation of conditional correlation between the multiple health outcomes (malnutrition status) and spatial dependence within the region and across regions. The results obtained provide a better understanding on spatial variations in the co-existence and etiology patterns of childhood undernutrition, which would have neglected in the standard spatial analysis. The output would inspire public health practitioners, epidemiologists, and policy makers to design a combination of intervention strategies and effective allocation of scarce health resources. Despite the complexity in the methodology, the result is reasonable and consistent with univariate analysis. The advantage of the multivariate approach is that it yields more precise estimates and easy interpretation of regressions coefficients defined in terms of odds ratios. A potential drawback, however is the huge computational burden involved in MCMC simulations. The researchers experience with the univariate models suggests that the two approaches provide similar results with respect to the direction and strength of predictor outcome associations.

\section{Abbreviations}

HAZ, Height-for-age z-score; OR, odd ratio; WAZ, Weight-for-age z-score; SSA- Sub-Saharan Africa; SES, socio-economic status; WHO, World Health Organization; WHZ, Weight-for-height z-score.

\section{Ethical clearance}

The permission was granted to use Demographic and Health Survey (DHS) data with all identifier information removed. The ethics approved by the survey Committee of the MEASURE Data, DHS, ORC Macro Calverton, USA. The malnutrition prevalence was summarized based on Geo-reference coordinates of the respondent at the cluster level and does not contain any individual identifier data. No ethical clearance was required from Research Ethics Committee of the University of Kwazulu-Natal or any other institution save for the aforementioned.

\section{Data availability}

The authors confirm that all data underlying the findings are fully available without restriction. The data is held by National Bureau of Statistics of respective countries. The link to access it is: http://www.measuredhs.com/aboutsurveys/dhs/sta

\section{Competing interests}

No competing interest declared.

\section{Authors contributions}

RAA, TZ and SR conceived the idea and designed the study. RAA proposed the model, performed analysis and wrote the initial draft. SR \& TZ advised on the methodology and interpreted the results. Both TZ and SR read the initial draft and made suggestions. RAA implemented the comments and revision of the manuscript. All authors read and approved the final version of the manuscript.

\section{Acknowledgments}

We would like to acknowledge the permission granted by MEASURE Data, Demographics and Health Surveys, 
Macro Calverton USA to use data sets from sub-Saharan African countries: Burkina Faso, and Mozambique under the project- Spatial Analysis of poverty, malnutrition and childhood mortality in Sub-Saharan Africa. The first author also appreciates the support of Federal University of Technology, Minna-NIGERIA for the postgraduate study fellowship/leave in South Africa.

\section{Funding}

No funding attached to this work.

\section{References}

1. UNICEF, UNICEF, et al. Who-the world bank joint child malnutrition estimates. Levels and trends in child malnutrition (updated September 2014). New York, NY, 2014.

2. WHO and World Bank. Worldwide prevalence of anaemia 1993-2005: Who global database on anaemia. World Bank Publications, 2008.

3. Ismael Ngnie-Teta, Olivier Receveur, and Barthelemy Kuate-Defo. Risk factors for moderate to severe anemia among children in benin and mali: insights from a multilevel analysis. Food and Nutrition Bulletin, 28(1):76-89, 2007. 4. WHO. Global technical strategy for malaria 2016-2030. World Health Organization, 2015.

5. Stephan Ehrhardt, Gerd D Burchard, Carsten Mantel, Jakob P Cramer, Sarah Kaiser, Martina Kubo, Rowland N Otchwemah, Ulrich Bienzle, and Frank P Mockenhaupt. Malaria, anemia, and malnutrition in african childrendefining intervention priorities. Journal of Infectious Diseases, 194(1):108-114 PubMed:16741889, 2006.

6. Gretchen A Stevens, Mariel M Finucane, Luz Maria De-Regil, Christopher J Paciorek, Seth R Flaxman, Francesco Branca, Juan Pablo Peña-Rosas, Zulfiqar A Bhutta, Majid Ezzati, Nutrition Impact Model Study Group, et al. Global, regional, and national trends in haemoglobin concentration and prevalence of total and severe anaemia in children and pregnant and non-pregnant women for 1995-2011: a systematic analysis of population-representative data. The Lancet Global Health, 1(1):e16-e25, 2013.

7. Leontine Alkema, Jin Rou New, Jon Pedersen, Danzhen You, et al. Child mortality estimation 2013: an overview of updates in estimation methods by the united nations inter-agency group for child mortality estimation. PloS one, 9(7):e101112, 2014.

8. Robert E Black, Cesar G Victora, Susan P Walker, Zu- lfiqar A Bhutta, Parul Christian, Mercedes De Onis, Majid Ezzati, Sally Grantham-McGregor, Joanne Katz, Reynaldo Martorell, et al. Maternal and child undernutrition and overweight in low-income and middle-income countries. The Lancet, 382(9890):427-451, 2013.

9. Claudia R Morris, Sylvia T Singer, and Mark C Walters. Clinical hemoglobinopathies: iron, lungs and new blood. Current Opinion in Hematology, 13(6):407-418, 2006.

10. Sammy Wambua, Tabitha W Mwangi, Moses Kortok, Sophie M Uyoga, Alex W Macharia, Jedidah K Mwacharo, David J Weatherall, Robert W Snow, Kevin Marsh, and Thomas N Williams. The effect of $\alpha+$-thalassaemia on the incidence of malaria and other diseases in children living on the coast of kenya. PLoS Medicine, 3(5):e158, 2006.

11. Jane Crawley. Reducing the burden of anemia in infants and young children in malaria-endemic countries of africa: from evidence to action. The American Journal of Tropical Medicine and Hygiene, 71(2 suppl): 25-34, 2004.

12. Sally Grantham-McGregor and Cornelius Ani. A review of studies on the effect of iron deficiency on cognitive development in children. The Journal of Nutrition, 131(2):649S-668S, 2001.

13. Jeanne W Lawless, Michael C Latham, Lani S Stephenson, Stephen N Kinoti, and Anne M Pertet. Iron supplementation improves appetite and growth in anemic kenyan primary school children. The Journal of Nutrition, 124(5):645-654, 1994.

14. Stephen J Oppenheimer. Iron and its relation to immunity and infectious disease. The Journal of Nutrition, 131(2):616S-635S, 2001.

15. Ricardo J Soares Magalhaes and Archie CA Clements. Mapping the risk of anaemia in preschool-age children: the contribution of malnutrition, malaria, and helminth infections in west africa. PLoS Med, 8 (6):e1000438 Crossref GoogleScholar, 2011.

16. Artemis Koukounari, Alan Fenwick, Sarah Whawell, Narcis B Kabatereine, Francis Kazibwe, Edridah M Tukahebwa, J Russell Stothard, Christl A Donnelly, and Joanne P Webster. Morbidity indicators of schistosoma mansoni: relationship between infection and anemia in ugandan schoolchildren before and after praziquantel and albendazole chemotherapy. The American Journal of Tropical Medicine and Hygiene, 75(2):278-286, 2006.

17. Ngianga-Bakwin Kandala, Tumwaka P Madungu, Jacques BO Emina, Kikhela PD Nzita, and Francesco P 
Cappuccio. Malnutrition among children under the age of five in the democratic republic of Congo (drc): does geographic location matter? BMC Public Health, 11(1):261, 2011.

18. Emanuela Dreassi. Polytomous disease mapping to detect uncommon risk factors for related diseases. Biometrical Journal, 49(4):520-529, 2007.

19. Alan R Dabney and Jon C Wakefield. Issues in the mapping of two diseases. Statistical Methods in Medical Research, 14(1):83-112, 2005.

20. Leonhard Held, Isabel Nat'ario, Sarah Elaine Fenton, $\mathrm{H}^{\circ}$ avard Rue, and Nikolaus Becker. Towards joint disease mapping. Statistical methods in medical research, 14(1):61-82, 2005.

21. Samuel Manda, Richard Feltbower, and Mark Gilthorpe. Review and empirical comparison of joint mapping of multiple diseases. Southern African Journal of Epidemiology and Infection, 27(4):169-182, 2012.

22. Amy Downing, David Forman, Mark S Gilthorpe, Kimberley L Edwards, and Samuel OM Manda. Joint disease mapping using six cancers in the yorkshire region of england. International Journal of Health Geographics, 7(1):41, 2008.

23. ICF INSD. International: Enqu^ete d'emographique et de sant'e et a indicateurs multiples du Burkina Faso 2010, 2012.

24. Mozambique National Statistics Institute:, Maputo, Mozambique and ICF Macro, Calverton, Maryland, USA. Mozambique Demographic and Health survey 2011. Mozambique: Mozambique Demographic and Health Survey, 2012, 2011.

25. The DHS program. Demographic and Health Survey, 2011 (accessed February 3, 2017). URL http:

//www.measuredhs.com/aboutsurveys/dhs/start.cfm.

26. UN DeSA et al. World population prospects: The 2017 revision. Population division of the department of economic and social affairs of the United Nations Secretariat, New York, 2017.

27. Rebecca J Stoltzfus. Rethinking anaemia surveillance. The Lancet, 349(9067):1764 PubMedGoogle Scholar, 1997.

28. World Health Organization et al. WHO child growth standards: length/height for age, weight-for-age, weightfor-length, weight-for-height and body mass index-forage, methods and development. World Health Organization, 2006.

29. Lawrence N Kazembe. An additive regression model for investigating the relationship between childhood health and socio-economic status. Spatial and Spatio-temporal epidemiology, 6:71-84, 2013.

30. Emily Smith-Greenaway and Jenny Trinitapoli. Polygynous contexts, family structure, and infant mortality in sub-saharan africa. Demography, 51(2):341-366, 2014.

31. Leonhard Knorr-Held and Nicola G Best. A shared component model for detecting joint and selective clustering of two diseases. Journal of the Royal Statistical Society: Series A (Statistics in Society), 164(1): 73-85, 2001. 32. Nicky Best and Anna Louise Hansell. Geographic variations in risk: adjusting for unmeasured confounders through joint modeling of multiple diseases. Epidemiology (Cambridge, Mass.), 20(3):400, 2009.

33. Thomas Waldhoer, Martin Wald, and Harald Heinzl. Analysis of the spatial distribution of infant mortality by cause of death in austria in 1984 to 2006. International Journal of Health Geographics, 7(1):21, 2008.

34. Damaris K Kinyoki, Samuel O Manda, Grainne M Moloney, Elijah O Odundo, James A Berkley, Abdisalan M Noor, and Ngianga-Bakwin Kandala. Modelling the ecological comorbidity of acute respiratory infection, diarrhoea and stunting among children under the age of 5 years in somalia. International Statistical Review, 85(1):164176, 2017.

35. Berta Iba'ñez-Beroiz, Julia'n Librero-Lo'pez, Salvador Peiro'-Moreno, and Enrique Bernal-Delgado. Shared component modelling as an alternative to assess geographical variations in medical practice: gender inequalities in hospital admissions for chronic diseases. BMC Medical Research Methodology, 11(1):172, 2011.

36. William J Browne, Harvey Goldstein, and Jon Rasbash. Multiple membership multiple classification (mmmc) models. Statistical Modelling, 1(2):103-124, 2001. 37. Mark Tranmer, David Steel, and William J Browne. Multiple-membership multiple-classification models for social network and group dependences. Journal of the Royal Statistical Society: Series A (Statistics in Society), 177(2):439_ 455, 2014.

38. Kathleen Mullan Harris, Carolyn Tucker Halpern, Brett C Haberstick, and Andrew Smolen. The national longitudinal study of adolescent health (add health) sibling pairs data. Twin Research and Human Genetics, 16(1):391-398, 2013.

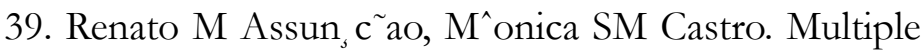
cancer sites incidence rates estimation using a multivariate bayesian model. International Journal of Epidemiology, 33(3):508-516, 2004.

40. Adrian Dobra, Alex Lenkoski, and Abel Rodriguez. 
Bayesian inference for general gaussian graphical models with application to multivariate lattice data. Journal of the American Statistical Association, 106 (496):1418-1433, 2011. 41. Ying C MacNab. On gaussian markov random fields and bayesian disease mapping. Statistical Methods in Medical Research, 20(1):49-68, 2011.

42. Peter Congdon. Representing spatial dependence and spatial discontinuity in ecological epidemiology: a scale mixture approach. Stochastic Environmental Research and Risk Assessment, 31(2):291-304, 2017.

43. David J Spiegelhalter, Nicola G Best, Bradley P Carlin, and Angelika Van Der Linde. Bayesian measures of model complexity and fit. Journal of the Royal Statistical Society: Series B (Statistical Methodology), 64(4):583-639, 2002.

44. Alan E Gelfand and Penelope Vounatsou. Proper multivariate conditional autoregressive models for spatial data analysis. Biostatistics, 4(1):11-15, 2003.

45. R Core Team. R: A language and environment for statistical computing. Foundation for Statistical Computing, Vienna, Austria. 2013, 2014.

46. Havard Rue and Leonhard Held. Gaussian Markov random fields: theory and applications. CRC Press, 2005. 47. Gadm database of global administrative areas, version 2.0.

48. Julian Besag, Jeremy York, and Annie Molli'e. Bayesian image restoration, with two applications in spatial statistics. Annals of the Institute of Statistical Mathematics., 43(1):1-20. CrossRef Google Scholar, 1991.

49. Stefan Lang and Andreas Brezger. Bayesian p-splines. Journal of Computational and Graphical Statistics, 13(1):183212, 2004.

50. Ludwig Fahrmeir, Thomas Kneib, Stefan Lang, and Brian Marx. Regression: models, methods and applications. Springer Science \& Business Media, 2013.

51. Ludwig Fahrmeir and Stefan Lang. Bayesian inference for generalized additive mixed models based on markov random field priors. Journal of the Royal Statistical Society: Series C (Applied Statistics), 50(2): 201-220, 2001. 52. Paul HC Eilers and Brian D Marx. Flexible smoothing with b-splines and penalties. Statistical Science, pages 89-102, 1996.

53. Julian Besag. Spatial interaction and the statistical analysis of lattice systems. Journal of the Royal Statistical Society. Series B (Methodological), pages 192-236, 1974.

54. JM Bernardo, MJ Bayarri, JO Berger, AP Dawid, D Heckerman, AFM Smith, and M West. Hierarchical multivariate car models for spatio-tempo rally correlated sur- vival data. In Bayesian Statistics 7: Proceedings of the Seventh Valencia International Meeting, page 45. Oxford University Press, USA, 2003.

55. Xiaoping Jin, Bradley P Carlin, and Sudipto Banerjee. Generalized hierarchical multivariate car models for areal data. Biometrics, 61(4):950-961, 2005.

56. KV Mardia. Multi-dimensional multivariate gaussian markov random fields with application to image processing. Journal of Multivariate Analysis, 24(2):265-284, 1988.

57. Sudipto Banerjee, Bradley P Carlin, and Alan E Gelfand. Hierarchical modeling and analysis for spatial data. Crc Press, 2014.

58. DJ Spiegelhalter, A Thomas, NG Best, and DJ Lunn. Winbugs: Bayesian inference using gibbs sampling manual, version 1.4. london: Imperial college; cambridge, uk: Mrc biostatistics unit, 2002 Available at: http:/www.mrcbsu.cam.ac.uk/bugs.

59. Md Israt Rayhan and M Sekander Hayat Khan. Factors causing malnutrition among under five children in bangladesh. Pak J Nutr, 5(6):558-62, 2006.

60. Shea O Rutstein. Effects of preceding birth intervals on neonatal, infant and under-five years mortality and nutritional status in developing countries: evidence from the demographic and health surveys. International Journal of Gynecology \& Obstetrics, 89(S1), 2005.

61. Gugsa Yimer. Malnutrition among children in southern ethiopia: Levels and risk factors. Ethiopian Journal of Health Development, 14(3), 2000.

62. Fredrick Kateera, Chantal M Ingabire, Emmanuel Hakizimana, Parfait Kalinda, Petra F Mens, Martin P Grobusch, Leon Mutesa, and Mich `ele Vugt. Malaria, anaemia and under-nutrition: three frequently co-existing conditions among preschool children in rural Rwanda. Malaria Journal, 14(1):440, 2015.

63. Ellen Van de Poel, Ahmad Reza Hosseinpoor, Caroline Jehu-Appiah, Jeanette Vega, and Niko Speybroeck. Malnutrition and the disproportional burden on the poor: the case of ghana. International Journal for Equity in Health, 6(1):21, 2007.

64. Dickson A Amugsi, Maurice B Mittelmark, and Anna Lartey. An analysis of socio-demographic patterns in child malnutrition trends using ghana demographic and health survey data in the period 1993-2008. BMC Public Health, 13(1):960, 2013.

65. M`onica M Os'orio, Pedro IC Lira, Malaquias Batista-Filho, and Ann Ashworth. Prevalence of anemia in children 6-59 months old in the state of pernambuco, 
brazil. Revista Panamericana de Salud Pu'blica, 10(2):101107, 2001.

66. Suying Chang, Li Wang, Yuying Wang, Inge D Brouwer, Frans J Kok, Betsy Lozoff, and Chunming Chen. Iron-deficiency anemia in infancy and social emotional development in preschool-aged chinese children. Pediatrics, 127(4):e927-e933, 2011.

67. Roland Pongou, Majid Ezzati, and Joshua A Salomon. Household and community socioeconomic and environmental determinants of child nutritional status in cameroon. BMC Public Health, 6(1):98, 2006.

68. Babatunde Omilola et al. Patterns and trends of child and maternal nutrition inequalities in nigeria. Technical report, International Food Policy Research Institute (IFPRI), 2010.

69. Beth Osterbauer, James Kapisi, Victor Bigira, Florence Mwangwa, Stephen Kinara, Moses R Kamya, and Grant Dorsey. Factors associated with malaria parasitaemia, malnutrition, and anaemia among hiv-exposed and unexposed ugandan infants: a cross-sectional survey. $\mathrm{Ma}$ laria Journal, 11(1):432, 2012.
70. Eline L Korenromp, Joanna RM Armstrong-Schellenberg, Brian G Williams, Bernard L Nahlen, and Robert W Snow. Impact of malaria control on childhood anaemia in africa-a quantitative review. Tropical Medicine \& International Health, 9(10):1050-1065, 2004.

71. Neil J Salkind. Encyclopedia of research design, volume 1. Sage, 2010.

72. Morten Gronbaek, Allan Deis, Thorkild IA Sorensen, Ulrik Becker, Peter Schnohr, and Gorm Jensen. Mortality associated with moderate intakes of wine, beer, or spirits. BMJ, 310(6988):1165-1169, 1995.

73. Archie CA Clements, Sonja Firth, Robert Dembel'e, Amadou Garba, Seydou Tour'e, Moussa Sacko, Aly Landour'e, Elisa Bosqu'e-Oliva, Adrian G Barnett, Simon Brooker, et al. Use of bayesian geostatistical prediction to estimate local variations in schistosoma haematobium infection in western Africa. Bulletin of the World Health Organization, 87(12):921-929, 2009.

74. Ngianga-Bakwin Kandala, Ludwig Fahrmeir, Stephan Klasen, and Jan Priebe. Geo-additive models of childhood undernutrition in three sub-saharan african countries. Population, Space and Place, 15(5): 461-473, 2009. 